\title{
Metal Nanotube/Nanowire-Based Unsupported Network Electrocatalysts
}

\section{Falk Muench $\mathbb{D}$}

Department of Materials and Earth Sciences, Technische Universität Darmstadt, 64287 Darmstadt, Germany; muench@ma.tu-darmstadt.de; Tel.: +49-6151-1621-994

Received: 31 October 2018; Accepted: 23 November 2018; Published: 1 December 2018

\begin{abstract}
Combining 1D metal nanotubes and nanowires into cross-linked 2D and 3D architectures represents an attractive design strategy for creating tailored unsupported catalysts. Such materials complement the functionality and high surface area of the nanoscale building blocks with the stability, continuous conduction pathways, efficient mass transfer, and convenient handling of a free-standing, interconnected, open-porous superstructure. This review summarizes synthetic approaches toward metal nano-networks of varying dimensionality, including the assembly of colloidal 1D nanostructures, the buildup of nanofibrous networks by electrospinning, and direct, template-assisted deposition methods. It is outlined how the nanostructure, porosity, network architecture, and composition of such materials can be tuned by the fabrication conditions and additional processing steps. Finally, it is shown how these synthetic tools can be employed for designing and optimizing self-supported metal nano-networks for application in electrocatalysis and related fields.
\end{abstract}

Keywords: metal nanowires; metal nanotubes; free-standing nano-architectures; nanostructure interconnection; unsupported heterogeneous catalysts; fuel cells; electrochemical sensors

\section{Introduction}

Distributing metal nanoparticles onto high surface area supports represents a prominent catalyst optimization paradigm for improving metal utilization and activity. In such heterogeneous catalyst systems, the support plays multiple roles: It stabilizes the nanoparticles, can modify their reactivity, and (due to usually being present in great excess) markedly affects the catalyst layer structure, in which open porosity is required to ensure accessibility of the active sites. In cases of electrocatalysis, the support also acts as a conductive backbone. However, support utilization comes with drawbacks, such as susceptibility to aging. For instance, carbon support corrosion, which is accompanied by activity loss, metal nanoparticle agglomeration/detachment, and catalyst layer compaction, represents a major issue in fuel cell durability [1]. Also, at high loadings, deeper catalyst regions tend to be occluded, resulting in diminishing returns with respect to metal utilization $[2,3]$.

Thus, efforts to improve support performance [4] are paralleled by an outright opposing strategy, aiming for a complete elimination of the support, which is accompanied by skillful nano- and microstructuring to alleviate potential disadvantages [5-8]. For unsupported heterogeneous catalysts, structural tailoring on multiple length scales is vital to overcome the intrinsic problem of achieving good mass activity with materials built solely from metal. On the nanoscale, a high surface area and density of active sites must be ensured alongside durability and efficient exposure of the catalyst material, while the larger scale catalyst architecture is important for achieving efficient mass transfer, electrical conductivity, and mechanical stability.

In this regard, 1D metal nanostructures such as nanotubes and nanowires have garnered considerable attention [5,7-12]. Due to their pronounced anisotropy, they provide extended electrical 
conduction paths [3]. The typically observed high long-term stability of metal nanotubes and nanowires $[2,10,11,13]$, which is related to their resistivity toward common catalyst degradation mechanisms. Due to the lack of support corrosion and their coherent structure, nanoparticle detachment, nanoparticle agglomeration, and Ostwald ripening are less relevant to those materials. In addition, the surface or mass-normalized activities of optimized 1D nanostructures can surpass those of classical metal blacks, nanopowders, and supported nanoparticles [2,10,11,13].

Using metal nanowires and nanotubes as building blocks for creating interconnected superstructures opens up new avenues for further functionality improvement and tuning. Such nano-networks maintain the aforementioned characteristics of the individual nanostructures, while complementing them with the additional benefits of an organized superstructure. For instance, drop-casting a Ag nanowire colloid to form a thin, percolating 2D layer results in a rather high electrical resistance due to the large contact resistance between the individual nanowires [14]. Merging those wires into an interconnected network is the foundation for translating the excellent conductivity of the individual building blocks into a macroscale 2D superstructure [14]. Combining nanowires and nanotubes into 3D networks offers the possibility to build up monolithic, nanostructured catalysts with high porosity, surface area, activity and robustness [2,13].

This review focuses on strategies for fabricating interconnected metal nanowire and nanotube architectures, as well as on implications of the synthetic control over structure and composition on designing and improving materials for electrocatalysis and related applications. Following the synthetic theme, the discussion is structured with respect to the network dimensionality, and subdivided by the general fabrication strategy. It excludes nano-networks composed of other materials (e.g., carbon, oxides, semimetals or conducting polymers [15-19]), which can be obtained with similar approaches to those outlined in this review, as well as nanostructured metals, that can be described as networks, but which are not created from 1D building blocks. This involves the popular nanoporous metals (most prominently, nanoporous Au [20]), which are composed of low aspect ratio ligaments formed by self-ordered segregation during the de-alloying of solid precursor structures, likewise to the well-established Raney Ni catalysts [21], or which can be created by block copolymer templating [22]. Similarly, 3D metal aerogels or 2D interconnected layers formed by the aggregation of 0D nanoparticles [23,24], which are sometimes also termed "nanowire networks" [24,25], are not covered here. For those materials, the reader is referred to the large number of recent reviews, which provide an excellent overview of nanoporous metals [20,22,26,27] and 3D metal nanoparticle aggregates $[22,27,28]$. In the Supplementary Material, the reader can find tables summarizing the nano-network examples discussed here, sorted by section.

While plentiful reviews cover the topics of 1D metal nanostructures (and their parallel arrays), the work on purposefully interconnected 2D and 3D superstructures is much more fragmented, particularly when seen from the viewpoint of heterogeneous catalysis. Two-dimensional metal nanowire networks are intensively researched, but almost exclusively in the context of transparent conductors. Unsupported 3D metal nano-network catalysts play a role at the intersection of the fuel cell and electrospinning communities. In this field, a thorough understanding of both the nanostructure and the macroscale architecture of the catalyst layer (and their respective impacts on the device functionality) is strived for, whereas most articles concerned with electrocatalytic performance of colloidal 1D nanostructures (which need to be assembled into catalyst layers as well) focus their efforts on the individual nano-object. Ion-track etched polymer templates grant the ability to almost arbitrarily vary the nanostructure density, organization, and diameter. This allows nano-networks to be designed with set free volume, inner surface area, and interconnectivity, and to pinpoint crucial properties such as mechanical stability, electrical/thermal conductivity, accessibility, and metal loading. The opportunities provided by this exceptional degree of synthetic freedom are far from being utilized.

The intention of this review is to contribute to a better connection between these fields, in order to assist in identifying similarities, synergies, and opportunities for further research. For instance, the welding techniques employed for joining $1 \mathrm{D}$ metal nanostructures into $2 \mathrm{D}$ networks could as 
well serve for constructing robust monolithic 3D catalyst architectures out of the same building blocks. And the burgeoning field of template-designed 3D nano-networks could take advantage of the rich experience that exists for the compositional and structural tuning of 1D constituents in related approaches. Hopefully, both the beauty of and the intricacies associated with the nanostructures compiled in this work will spark enthusiasm for furthering the rational design of multiscale catalyst architectures.

\section{2D Nano-Networks}

\subsection{Preparation from Colloidal Building Blocks}

Percolating 2D nanowire films are commonly prepared from arrangements of individual nanowires, which are synthesized as colloids by chemical reduction, and then transferred to a substrate via solution processing [29]. Interfacial assembly, followed by transfer of the nanowire film, represents an alternative option [30].

Most of the nanowires employed in this way possess a characteristic, pentagonal cross-section, which is linked to their defined nanostructure: The nanowires are fivefold twinned, expose (111) facets at their tips, and (100) facets along their sides [31] (Figure 1). This specific nanostructure is also key to the formation of the wire morphology by anisotropic growth, which is based on selective metal deposition on the terminating (111) facets, and the breaking of the high symmetry of the metal lattice by twinning. Due to the generality of this growth mode, pentagonal nanowires can be synthesized from a range of fcc metals, most importantly Ag [29] and Cu [29], but also from Pd [32] or Au [33]. Colloidal routes toward metal nanowires with differing nanostructure are available as well, such as ultrathin Au [34] or Pt [35] nanowires.
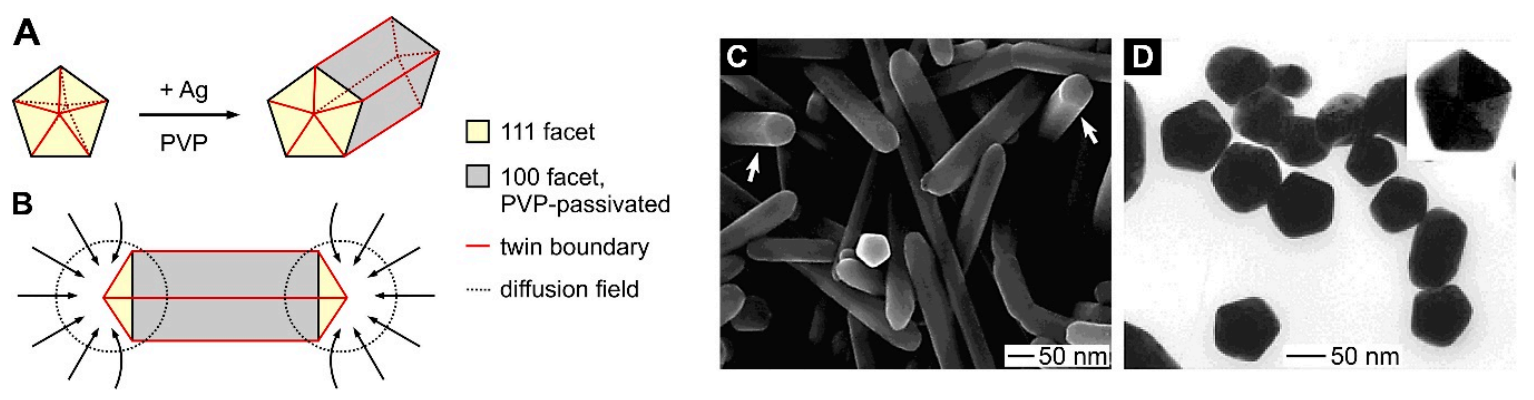

Figure 1. (A) Formation mechanism of pentagonal Ag nanowires, starting from fivefold twinned, decahedral, $\{111\}$-faceted seed nanoparticles, which elongate during growth due to the passivation of the evolving $\{100\}$ facets by polyvinylpyrrolidone (PVP). (B) Schematic side view of a growing nanowire, indicating the selective deposition of metal at the nanowire tips. (C) Scanning electron microscopy (SEM) image of Ag nanowires, in which the angular tips of some nanowires are highlighted. (D) Transmission electron microscopy (TEM) images of microtomed nanowires, corroborating their pentagonal cross-section. Reprinted (adapted) with permission from [31]. Copyright (2003) American Chemical Society.

To produce interconnected 2D networks, the nanowires in solution-deposited thin films are joined (Figure 2), which can be realized with different methods, including electroless plating, pressing, sintering, and halide-assisted and plasmonic welding [14,36-38]. 

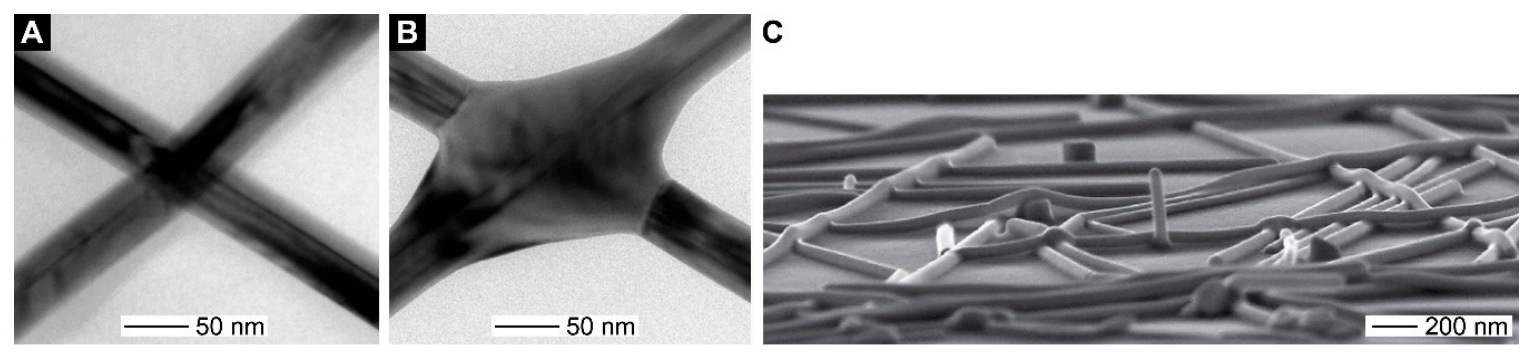

Figure 2. Electron micrographs of Ag nanowires before (A) and after (B) plasmonic welding, which causes the formerly stacked nanowires to merge. In the nanowire junction, the continuous twinning plane of one nanowire is maintained, while the second is thoroughly attached via recrystallization (B). (C) Tilted view of a merged 2D Ag nanowire film formed by plasmonic welding. Reprinted (adapted) with permission from [37]. Copyright (2012) Springer Nature Limited.

The highly anisotropic nature of the nanowire building blocks allows decoupling the electrical conductivity of metals from the reflectivity as another metal-intrinsic property, thus enabling the construction of a highly-translucent film out of a non-transparent material: With metal nanowires, fully percolated networks with continuous conduction paths can be realized at low surface coverages. High quality Ag 2D nanowire networks combine sheet resistances of a few tens of $\Omega$ sq $^{-1}$ with optical transmittances of $>90 \%$, and are thus able to challenge the predominant indium tin oxide (ITO) [29]. While the vast majority of such networks is employed as transparent conductors, they also provide interesting platforms for catalytic applications, as they can serve as transparent (as well as flexible) electrocatalyst layers. Along these lines, planar Ag nanowire networks have been utilized as flexible, amperometric $\mathrm{H}_{2} \mathrm{O}_{2}$ sensors (Figure 3) [39], and $\mathrm{Cu}$ nanowire networks were used in the hydrogen evolution reaction [40]. It should be noted that in such 2D nanowire networks, a trade-off between the nanowire areal density (and thus, the catalytically active surface area) and the optical transmittance has to be made.
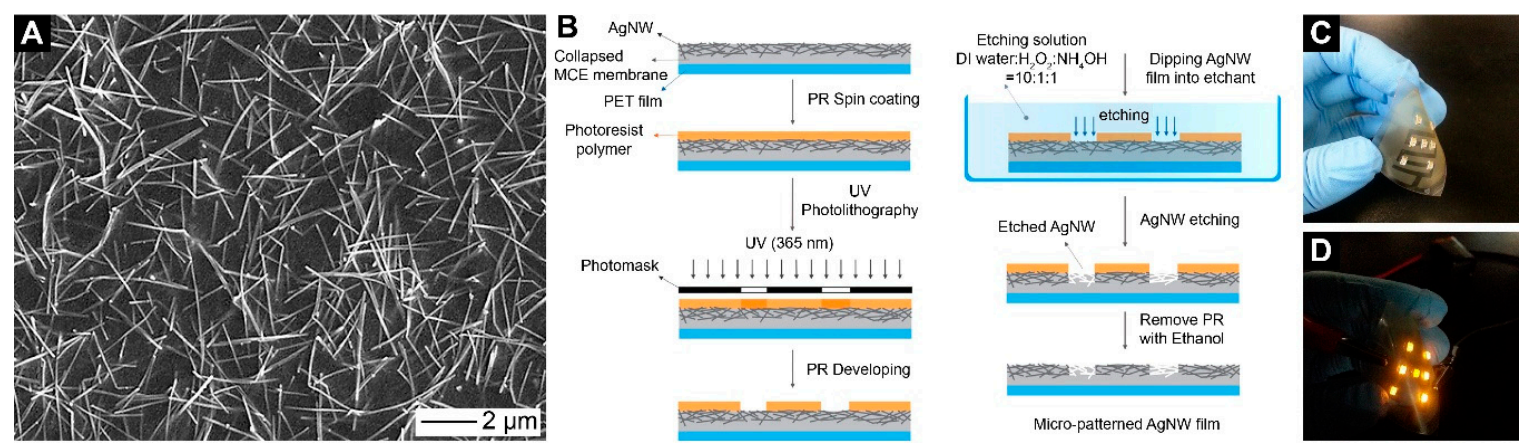

Figure 3. (A) Transparent Ag nanowire film supported by a collapsed mixed cellulose ester membrane. (B) Scheme of the photolithographic process used to pattern the Ag nanowire film. (C,D) Photographs of LED chips integrated on Ag nanowire electrodes with light off (C) and on (D), demonstrating the transparency, flexibility and conductivity of the nano-network films. Reprinted (adapted) with permission from [39]. Copyright (2015) Elsevier B.V.

To modify their properties and expand on their native catalytic functionality, 2D nanowire networks can also be modified. For instance, $\mathrm{Cu}$ networks have been overcoated with a $\mathrm{Pt}$ shell by electrodeposition in order to increase their activity in the hydrogen evolution reaction [41], and covered with graphene to protect them against corrosion [40].

Apart from building up networks from colloidal nanowires, solid 2D nanostructures such as nanoplates can also be partially broken down to form porous sheets. This subtractive manufacturing strategy was demonstrated for mesh-like 2D Pd nano-networks [42]. Due to the precisely defined crystallinity of the precursor nanoplates, the obtained Pd nanostructures consisted of meshes of 
aligned nanowires. In conjunction with the high surface area, the specific nanostructure facilitated a greatly-enhanced mass activity of the nano-meshes in ethanol electrooxidation both over the solid precursor nanoplates and carbon-supported Pd nanoparticles [42]. Also, the Pd nano-meshes represent promising base materials for creating synergetic catalysts: By adding $\mathrm{Pt}$ nanoparticles, superior hydrogen evolution catalysts could be obtained [42]. While this example is based on colloidal nanoplate precursors, transferring the approach to flat [43] or free-standing [44] nanoplate architectures and ultrathin metal films would provide a novel route toward 2D and 3D nanomesh architectures.

\subsection{Template-Assisted Deposition}

Aside from assembling individual nanowires into interconnected films, it is also possible to directly deposit planar metal networks. However, in this case, templates are required to define the specific nanostructure, as typical metal deposition methods (e.g., sputtering, electrodeposition, electroless plating, chemical vapor deposition, or evaporation) tend to yield more or less compact metal layers, not the interlinked, but otherwise mostly void architecture of 2D nano-networks.

Due to shadowing, sputtering results in preferential deposition at exposed substrate features. In combination with nanoporous anodized alumina as the template material, this deposition mechanism allowed the preparation of alumina-supported Pd nanowire networks, which have been applied in chemoresistive hydrogen sensing, showing very short response times due to the excellent accessibility and nanoscale dimensions of the Pd structures (down to $7 \mathrm{~nm}$ thickness) [45]. Although this sensing scheme is not based on a catalytic conversion, the same rationale applies to electrocatalytic amperometric sensors. Other templating approaches utilize electroless plating [46] or evaporation [47] to cover electrospun, 2D polymer nanofiber networks with metal. Due to the extremely long and continuous nature of the 1D nanofiber building blocks (and the resulting, outstanding percolation efficiency), very high conductivities and transparencies can be achieved simultaneously with electrospun templates (Figure 4). Extremely thin electrospun nanofiber films can also be enriched with metal precorsors, and converted into metallic networks, as outlined in Section 3.3 in more detail. Two-dimensional Pt nanowire networks prepared this way have been applied as multifunctional component in dye-sensitized solar cells, in which they simultaneously act as electrocatalyst and transparent conductive layer [48].

A

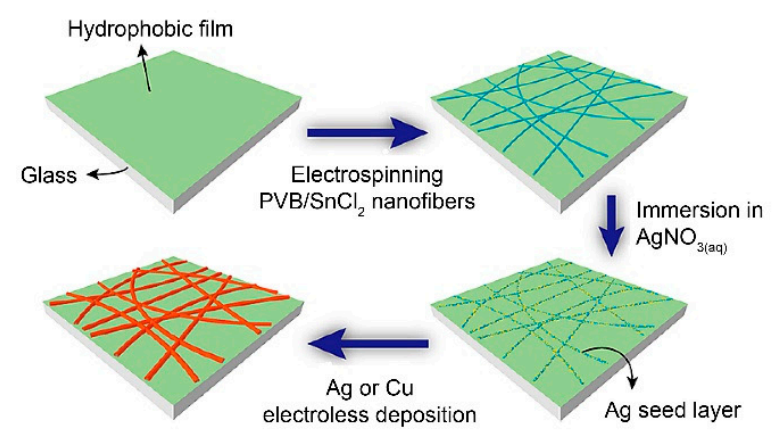

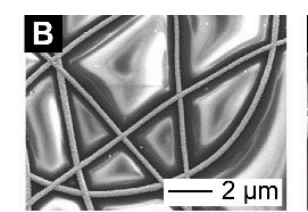
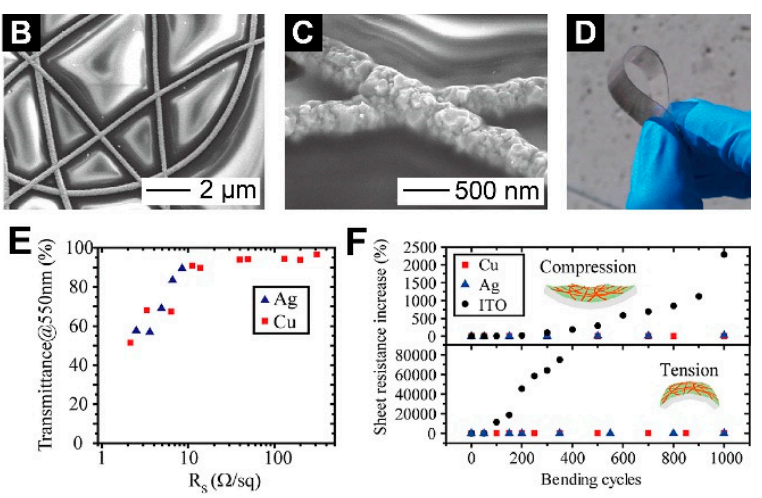

Figure 4. (A) Synthesis scheme for 2D transparent metal nano-networks fabricated with electrospun fiber templates (based on polyvinyl butyral (PVB)), which are selectively seeded and metallized with electroless plating. (B) SEM image of a Cu nano-network. (C) SEM detail image of a junction in a Ag nano-network. (D) Photograph of a Cu nano-network electrode deposited on a flexible poly(ethylene terephthalate) substrate. (E) Transmittance of $\mathrm{Ag}$ and $\mathrm{Cu}$ nano-networks of varying areal nanowire density, showing the trade-off between conductivity and transparency. (F) Change of the nano-network sheet resistance during repeated bending, showing excellent durability as compared to the brittle ITO. Reprinted (adapted) with permission from [46]. Copyright (2014) American Chemical Society. 
Metal evaporation in conjunction with grain boundary lithography represents a route toward mesh-like 2D metal nanowire networks [49]. Ordered 2D metal nanowire networks can be obtained by transfer of grating-templated parallel nanowire arrays [50].

\section{3D Nano-Networks}

\subsection{Preparation from Individual $1 D$ Nanostructures}

By simply increasing the amount of drop-coated nanowires, the approach outlined in Section 2.1 can be used to pile up nanowire films of increasing thickness [51], which resemble 3D networks. With this approach, amperometric glucose sensors have been constructed using Prussian blue modified Ag nanowires [52] and $\mathrm{Cu}$ nanowires [51]. Pentagonal Ag nanowires also have been employed in the electrochemical reduction of carbon dioxide [53]. Due to the large aspect ratio of the 1D building blocks, the resulting layers are inclined to have a very high porosity, characterized by an open-porous structure with a large fraction of macropores, which is beneficial for applications in catalysis and sensing, and contrasts the more crowded morphology of catalyst layers derived from particulate building blocks. Defect engineering represents an important aspect for tuning the catalytic properties of nanowires [54].

Similarly, networked architectures can be created from metal nanotube suspensions. While it is often not explicitly mentioned, and the catalyst layers are rarely characterized in detail, it can be assumed that many of the studies utilizing metal nanotube electrocatalysts actually employ such network-like architectures. The dispersed metal nanotubes used for the network buildup can be obtained by various methods. Galvanic replacement of colloidal silver, copper, or tellurium nanowires with a more noble metal (e.g., Pt [11,55-57], Pd [56,58], Au [58]) or metal combinations (e.g., Au-Pt [59], Pd-Pt [11,56], Pt-Ru [60]) is a common approach. It should be considered that even in the case of replacement with a single metal, the commonly occurring incompleteness of the exchange reaction-and/or accompanying purification steps intended to remove the residual educt metal-will result in bimetallic systems, in which a considerable impact of the composition on the catalytic performance is to be expected [61]. By applying galvanic replacement reactions or Kirkendall transformations on metal nanotubes instead of nanowires, double-walled or porous nanotubes can be created [61-63].

Also, parallel arrays of metal nanotubes deposited in porous membranes with different methods (e.g., electroless plating [63-67] or chemical vapor deposition [68]) can be released from the template, and then drop-coated to form unsupported catalyst networks. Such template membranes also can be combined with secondary templates like polymer spheres [69] or surfactants [70] to modify the internal morphology and porosity of the deposited nanostructures. A summary of the most common methods for preparing solid and porous 1D metal nanostructures can be found in Figure 5. Neither is this list exhaustive, nor are the named techniques necessarily limited to specific product morphologies. For instance, likewise to shape-controlled colloidal syntheses, electroless plating can yield 1D nanostructure deposits without templates by utilizing anisotropic growth [71], and electrodeposition can be tuned to produce nanotubes in porous templates $[72,73]$.

Metal nanotubes have been mainly applied in fuel cell catalysis, including both anodic and cathodic reactions (e.g., oxygen reduction $[11,56,57,72]$ and the oxidation of methanol $[55,58-61$, 64,68] and other alcohols [58]). In the future, it is necessary that these promising initial studies, which mostly remain limited to individual half reactions performed on model working electrodes, will be more frequently complemented by experiments which properly integrate such catalysts into membrane electrode assemblies [74]. The unsupported, extended, and hollow nature of nanotubes lends itself to the production of catalysts with high surface area and activity, which can be enhanced, e.g., by multi-element synergy $[11,56,61,64]$, the presence of defects such as grain boundaries [64], or pores $[65,66]$. Nevertheless, it is challenging to outperform conventional catalysts on the basis of noble metal mass or cost, which can be realized with careful tuning of the nanotube structure and 
composition $[11,56,59]$. Metal nanotubes often possess considerably enhanced electrochemical aging stability as compared to carbon-supported and metal black reference catalysts [11,57].

A

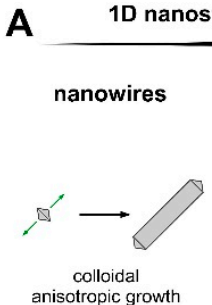

colloidal
anisotropic growth

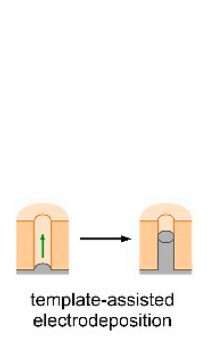

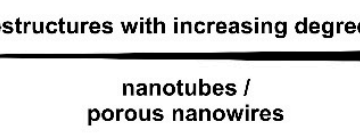

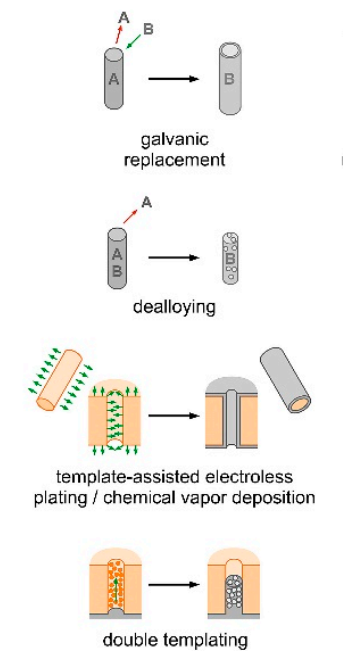

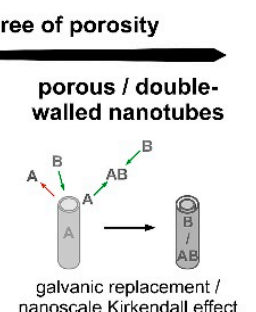
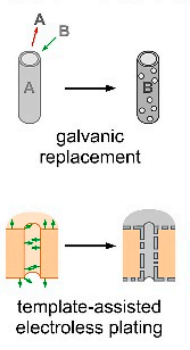
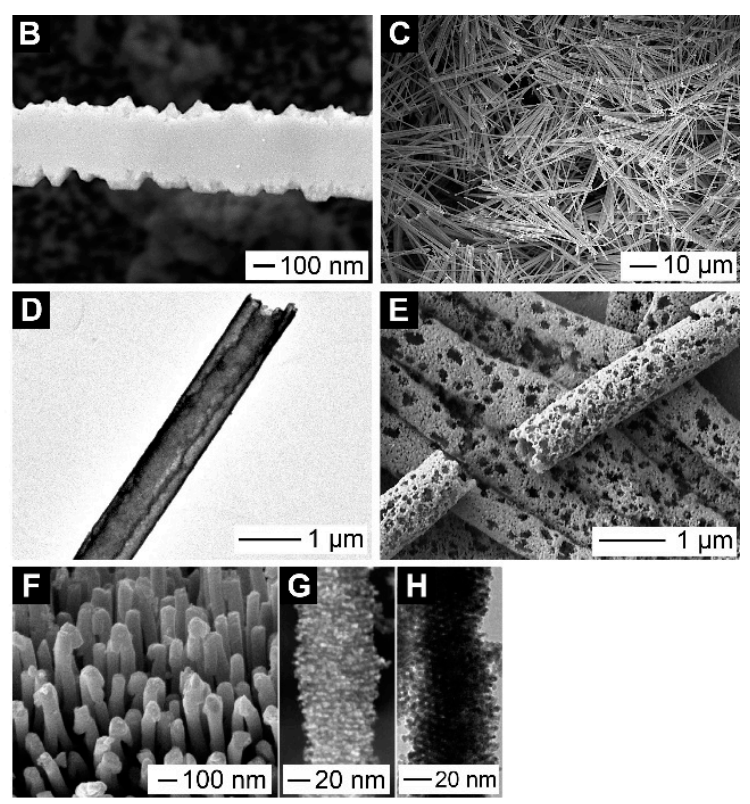

Figure 5. (A) Scheme of synthetic approaches toward 1D metal nanostructures, ordered by their degree of porosity. The green arrows indicate metal deposition, the red arrows metal dissolution. On the right, electron micrographs of representative nanostructures created with the named approaches are shown: (B) Jagged Ag nanobelt, obtained by colloidal anisotropic growth, based on the solution chemistry outlined in [44]. (C) Ag nanotubes, electrolessly deposited in ion-track etched polycarbonate templates, prepared according to [67]. (D) Double-walled Ag-Pt nanotube, prepared by galvanic replacement, according to [61]. (E) Ag nanotubes, which have been subjected to galvanic replacement with Au to create porous Ag-Au nanotubes, prepared according to [67]. (F-H) Mesoporous Pt nanowires, prepared with the double templating strategy, reprinted (adapted) with permission from [70]. Copyright (2008) American Chemical Society.

Despite the already expedient network architecture that can be achieved with this crude assembly strategy (a representative catalyst layer configuration can be seen in Figure 5C), the level of structural control remains limited: 1D nanostructures tend to align parallel to the substrate surface, and the overall porosity and nanostructure orientation within the piled films is difficult to adjust. Instead of being drop-coated, nanowire suspensions can be transformed into 3D networks with extremely low density by gelation [75,76] or freeze-casting [77], followed by supercritical [75] or freeze-drying [76,77]. With this approach, the low percolation threshold of high aspect ratio 1D nanostructures, which is the basis for the fabrication of 2D transparent conductors, can be exploited for designing ultralight 3D networks. Using the freeze-casting technique, the network density can be continuously adjusted, and stable Pd nanowire networks down to $0.1 \%$ of the bulk metal density could be obtained [77]. One additional advantage of this approach lies in its capability of producing monolithic nano-networks of arbitrary dimensions (Figure 6). While the scalability of wet-chemical, template-free syntheses makes it convenient to employ colloidally produced 1D nanostructures in gelation assembly and related techniques [76], it is also possible to utilize template-deposited nanostructures (e.g., Pd nanowires electrodeposited in nanoporous anodized alumina [77]). 
A

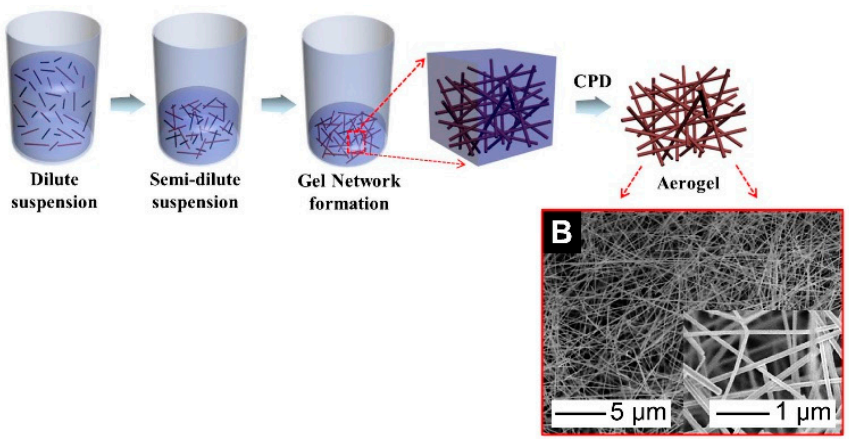

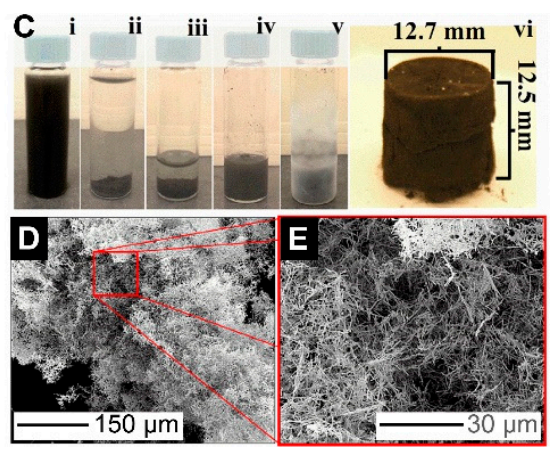

Figure 6. (A) Scheme of the fabrication of nanowire aerogels, based on gelation of nanowire suspensions, followed by critical point drying (CPD), including SEM images of a Ag nanowire aerogel (B). (A,B) are reprinted (adapted) with permission from [75]. Copyright (2012) Springer Nature Limited. (C) Preparation of 3D palladium nanowire networks via freeze-casting and freeze-drying, starting from a nanowire suspension (i), which after settling (ii) is adjusted to the desired volume (iii), redispersed (iv), and frozen in liquid nitrogen (v), yielding a monolithic sponge after freeze-drying (vi). (D,E) SEM images of a freeze-dryed Pd nanowire network. (C-E) are reprinted (adapted) with permission from [77]. Copyright (2017) American Chemical Society.

Contrasting their 2D counterparts, in the field of 3D nanowire and nanotube networks, there is a noteworthy lack of efforts to thoroughly interconnect the nanowires after aggregation (akin to the merging approaches mentioned in Section 2.1). Regarding electrocatalytic application, loss of nanostructures from those networks (e.g., during reactions with gas evolution or electrolyte flow), the detachment of drop-coated catalyst layers from the working electrode, and the need for binders represent typical problems. These issues can negatively affect the performance of catalyst layers built from unconnected 1D nanostructures, as compared to self-supported arrays or networks (see Figure 7A, architectures (ii) versus (iii), (v) and (vi)) [78]. Thus, it can be anticipated that the interlinking quality of these networks-together with associated properties such as stiffness, conductivity, or durability-as well as anchoring them to the electrode, leave quite some room for optimization.

\subsection{Template-Assisted Deposition}

Despite the possibilities available for assembling individual 1D nanostructures into 2D and 3D superstructures (Sections 2.1 and 3.1), a deposition of already connected networks is possible, with which a more direct control over the network and pore architecture can be exerted. Template-assisted synthesis routes provide an exceptionally versatile route to force the highly isotropic metals into such intricate patterns. In order to create interconnected 3D metal nano-networks, a shape-defining network of either pores or fibers is required, which is filled or overcoated during metal deposition. Directly depositing metal nano-networks makes it possible to avoid intermediate processing steps, such as nanowire synthesis, purification, aggregation, and merging, while the fabrication of the template (and its oftentimes required removal prior to application) adds to the complexity of the nano-network production.

Two privileged types of porous template membranes, which are commonly used for the deposition of parallel arrays of 1D nanostructures (nanotubes as well as nanowires), namely nanoporous anodized aluminium oxide [79,80] and ion-track etched polymer foils [80,81], can be modified to yield interconnected 3D nano-networks.

\subsubsection{Nanoporous Anodized Alumina Templates}

During the fabrication of nanoporous anodized alumina, the anodization conditions can be modulated (e.g., the temperature [82] or the anodization potential [83]), resulting in the controllable formation of weak spots (alumina of reduced chemical stability, or with reduced wall thickness) at defined positions in the self-ordered pore arrays. By etching out these weak spots after anodization, 
horizontal interconnections between the vertically-aligned pores can be created. Similar, but more randomly-distributed interconnections emerge during the anodization of low-cost aluminum foils containing impurities such as $\mathrm{Cu}$ (Figure 7A, architecture (v)) [84,85].
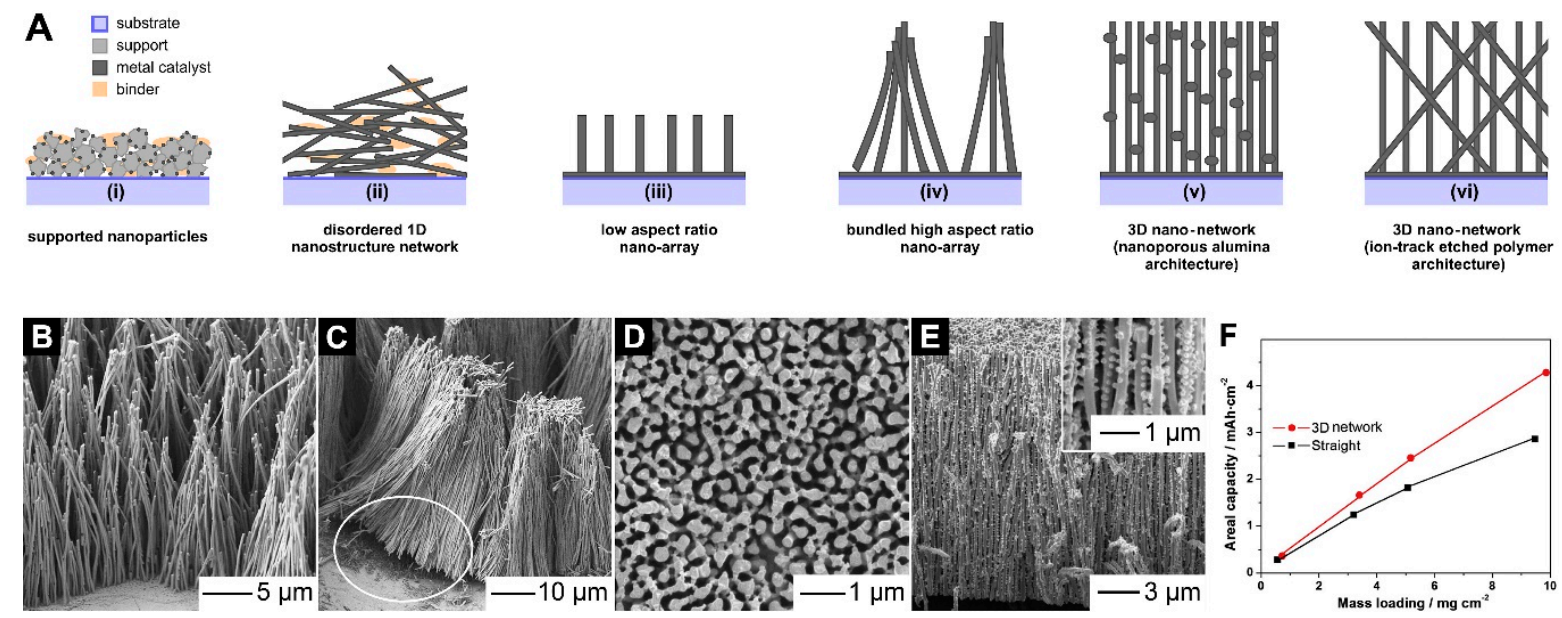

Figure 7. (A) Scheme of different catalyst layer architectures discussed throughout this work. (B-E) Different Ni-Sn nanowire architectures obtained by electrodeposition in nanoporous anodized alumina. (B) Moderate bundling of $20 \mu \mathrm{m}$ long nanowires. (C) Pronounced bundling of $40 \mu \mathrm{m}$ long nanowires. The circle highlights an area of marked nanowire detachment due to stress caused by bending. (D) Top view of an interconnected 3D nanowire network. (E) Side view of the nanowire network shown in (D). (F) Areal capacity of different Ni-Sn nanowire architectures, showing a linear relationship with the nanowire mass / length in the case of the 3D networks (type (v) in (A)), and a decreasing utilization for the parallel array architecture (type (iii/iv) in (A)). (B-F) reprinted (adapted) with permission from [85]. Copyright (2012) Elsevier B.V.

By filling the as-obtained interconnected pore arrays in such alumina membranes, nano-networks are obtained as the inverse replica of the template structure (Figure 7A, type v) [83]. Metal filling is commonly realized by electrodeposition, followed by etching of the remaining alumina walls to uncover the obtained nano-networks [84-86]. As a result of the typically high pore density of nanoporous alumina, which is intrinsically linked to the self-ordered pore formation [79], the networks obtained in such templates are relatively dense [83-86]. In electrochemical applications, such horizontally linked nano-networks show clear advantages compared to their unconnected counterparts (Figure 7B-F): Parallel 1D nanostructure arrays tend to form bundles $[85,87,88]$, which causes inhomogeneities in the array architecture, compaction and surface area loss at the bundle tips, and stress (most pronounced at the bottom of the nanostructures), making the system susceptible toward nanostructure detachment or breaking (Figure $7 \mathrm{~B}, \mathrm{C}$ ). This degradation mechanism is more severe in the case of $1 \mathrm{D}$ nanostructures of higher aspect ratio (length/diameter; see Figure 7A, architecture (iii) versus architecture (iv)) [78,85].

In contrast, well-crosslinked nanostructures retain their integrity after template removal, even in the case of high aspect ratios (i.e., low thickness and/or considerable length, Figure 7D,E). Such materials often exhibit a constant ratio of the electrochemically-utilized surface area and the metal loading (Figure 7F), which is a defining feature of openly accessible, free-standing architectures created from low-dimensional building blocks [2,44]. Interconnected nano-networks with many branching points also reliably provide continuous conduction pathways. These characteristics make them valuable for electrochemical applications which benefit from comparably high metal content (and the extended surface provided by it). This includes high capacity nanostructured batteries [85] and catalysts with high metal loading [2], to be applied, e.g., in reactions with sluggish kinetics $[3,89]$. Conversely, the high metal content and well-accessible architecture of nano-networks makes it possible to realize the given metal loadings with comparably thin catalyst layers, which is helpful for improving 
mass transfer, and amending flooding issues in fuel cells [74]. Due to the intrinsic proton conductivity that has been observed for unsupported metal nanostructures such as nanowires, the ionomer/binder component in fuel cell electrodes can be reduced in content [74], or perhaps even completely omitted, which further facilitates the mass transfer in such catalyst layers.

\subsubsection{Ion-Track Etched Polymer Templates}

Track etched polymer membranes are produced by selectively etching out the damaged material that swift heavy ions create during their passage through the polymer alongside linear trajectories [81]. Contrary to the formation of nanoporous anodized aluminum oxide, which is caused by self-organization, each pore in such a membrane can be correlated with a single ion trajectory, and thus, an externally controllable input. Together with the etching conditions, which define the pore diameter and shape [81], this provides the means for the extraordinary level of structural control. The density and orientation of the swift heavy ions used for irradiation can be well adjusted, and directly correspond to the orientation and density of the pores in the final membrane. Already etched ion track membranes can be subjected to further ion irradiation and etching steps, which introduce additional arrays of narrower pores, and enable the production of templates with hierarchical porosity [90]. By replacing the (mostly) isotropic polymers as the template matrix with anisotropic crystalline solids such as mica, it is also possible to create pores with angular cross-section [91], although such an architecture has not yet been realized in a network configuration.

In summary, a large number of important porosity parameters (pore diameter, length, shape, orientation, density) can be adjusted independently of each other, and in a markedly wide range [81]: Pore diameters as low as $\sim 10 \mathrm{~nm}$ can be realized, and continuously increased up to multiple microns. Membranes containing singular pores can be obtained, as well as variants with pore densities of $10^{9} \mathrm{~cm}^{-2}$ and higher. The pore diameter and density jointly define the probability of pore overlap. The pore length is defined by the template thickness and the pore inclination, and can reach more than $100 \mu \mathrm{m}$, depending on the kinetic energy (and thus range) of the ions. Adjustment of the pore inclination and the simultaneous presence of multiple pore orientations allows the production of ordered 3D networks with specific degrees of crosslinking. Finally, the process is compatible with different polymers (e.g., polyethylene terephthalate, polycarbonate, polyimide, polyvinylidene fluoride), making it possible to tune the properties of the template matrix as well. This has synthetic relevance: The polymer type strongly affects the accessible pore structures (pore shape/pore wall topology), which determine the morphology of the deposited nanostructures. Furthermore, the chosen polymer must be compatible with the reaction conditions during metal deposition, and endure the potentially occurring chemical/thermal stress [65,92].

Frequently, the polymer foils are irradiated only from a single direction before etching, perpendicular to their surface. Similar to conventional nanoporous alumina membranes, metal deposition within such templates results in the formation of a parallel array of 1D nanostructures (Figure 7A, architectures (iii) and (iv)), which however are randomly distributed [64-67] and miss the natural or artificially impressed order of the alumina membranes [79]. If the heavy ion irradiation is performed from multiple directions, crossing pores can be created, whose degree of interconnectivity is defined by the pore density, orientation, and diameter [93]. Such template membranes open the path toward precisely-defined 3D nano-networks (Figure 7A, architecture (vi)), which-depending on the choice of the metal deposition method and the deposition conditions [90]—can be composed of nanotubes as well as nanowire subunits (Figure 8).

Electroless plating features a conformal growth mechanism, in which the autocatalytic metal deposition is usually initiated by nanoparticles immobilized on the template pore walls. The particles continue to grow and merge, ending with coherent metal films [91]. Thus, this method tends to produce nanotubular morphologies, albeit wire-like structures can be obtained at extended deposition times $[90,91]$. The required metal nanoparticle seeds can be homogeneously deposited onto the template surface using different approaches, such as the conventional sensitization-activation chemistry 
of electroless plating $[91,94]$ or the reaction of metal ions with absorbed reducing agents at the polymer-solution interface [95]. Oxidation treatments can be used to increase the template polarity and metallization efficiency [96]. Aside from serving as seeds, these nanoparticles also can fulfil active roles in the final nanostructures. For instance, Pd nanoparticles have been embedded in the walls of Ni-Co nanotubes, making it possible to capitalize on the high catalytic activity Pd while using a common metal for establishing the more material-intensive nanotube support structure [97].

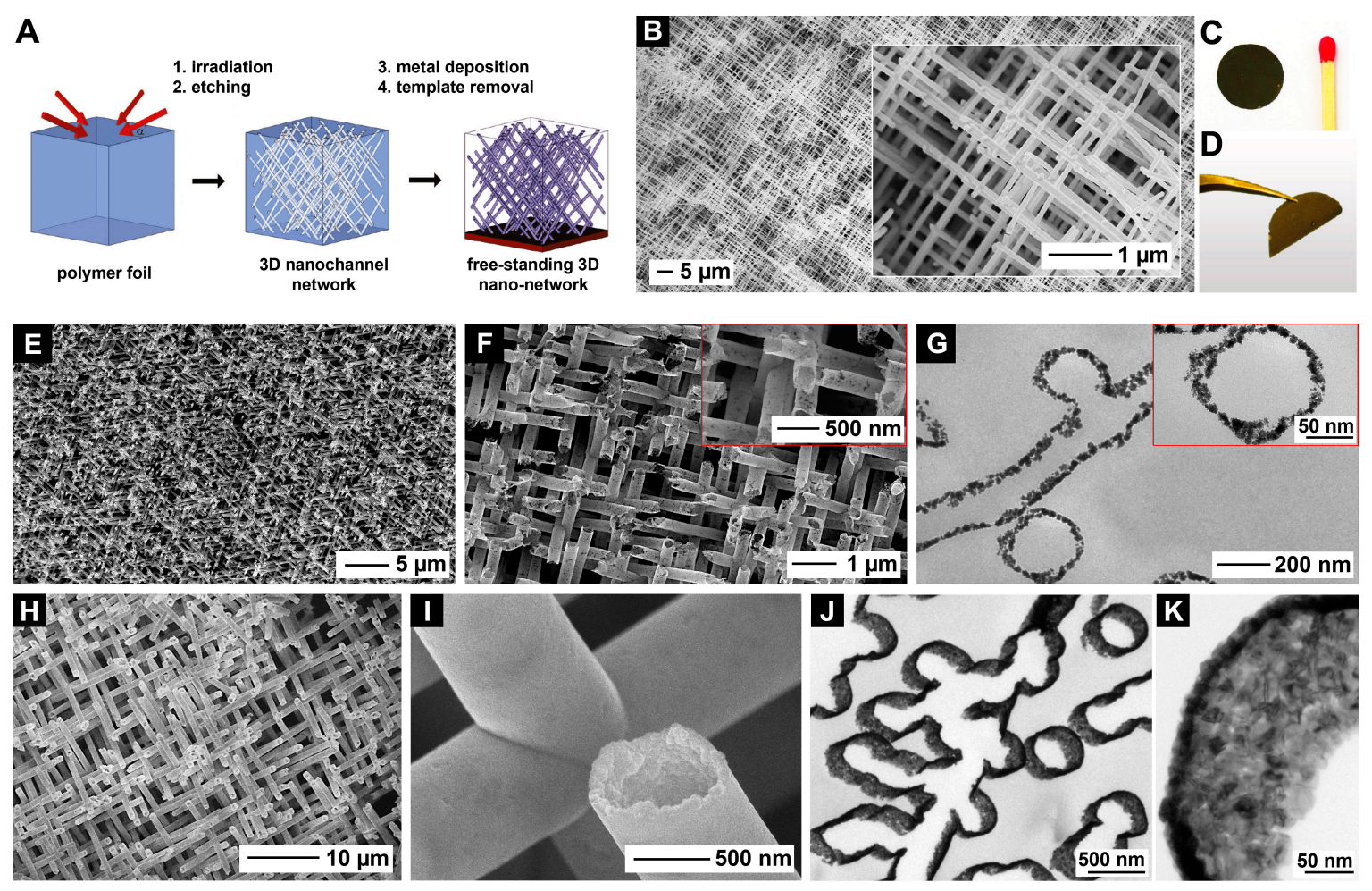

Figure 8. (A) Scheme of the fabrication of 3D nano-networks using ion-track etched polymer templates. (B) Electrodeposited 3D Pt nanowire network. (C,D) Photographs illustrating the size and the robust, free-standing nature of 3D Pt nanowire networks, which allows manipulating them with tweezers. (A-D) reprinted (adapted) with permission from [2]. Copyright (2011) American Chemical Society. (E-G) Electron micrographs of a porous Pt nanotube network optimized for metal utilization, reprinted (adapted) with permission from [98]. Copyright (2018) John Wiley and Sons. (H) SEM survey image of a Cu nanotube network possessing a density $2.8 \times 10^{7}$ nanostructures per $\mathrm{cm}^{2}$ and a comparable large outer tube diameter of $\sim 800 \mathrm{~nm}$. (I) SEM detail image of the network shown in $(\mathbf{H})$, displaying a nanotube crossing. (J,K) TEM images of a microtome cross-section of a 3D Au nanotube network, which despite its ultrathin wall diameter of $\sim 20 \mathrm{~nm}$ is free-standing due to the efficient nanostructure interconnection. Reprinted (adapted) with permission from [13]. Copyright (2015) John Wiley and Sons.

By applying electroless plating to ion-track etched templates irradiated from multiple directions, self-supported 3D metal nanotube networks have been fabricated from several catalytically interesting transition metals, including Ni [13], Pt [13,98], $\mathrm{Cu}$ [13], Ag [13], and Au [13]. Due to the high degree of interconnection ensured by the presence of multiple inclined pore arrays, 3D nanotube networks can be isolated from the template membrane by polymer dissolution without damaging their free-standing structure, even at very high porosities of more than 90\% [13]. Using ion-track etched templates with multiple pore diameters, hierarchical nanotube and nanowire networks can be obtained, depending on the degree of pore filling (Figure 9) [90]. The formation of nanotubes with porous walls can be facilitated by reducing the density of nucleation sites and by stopping the electroless plating reaction at intermediate stages $[66,98]$. Alternatively, electroless plating reactions can be chosen which produce intrinsically porous, polycrystalline deposits [65], and pores can be retroactively 
introduced by restructuring the nanotube walls (e.g., via galvanic replacement [67]). When using galvanic replacement, it must be considered that this technique tends to produces inhomogeneous deposits on complex educt architectures (e.g., caps on the tips of bundled nanowire arrays [87]), due to spatially-decoupled oxidation and reduction reactions. This issue is expected to be even more severe for 3D nano-networks, particularly for variants exhibiting comparably low porosity and/or pore size. Inspiration to overcome such difficulties could be derived from the field of colloidal nanostructure transformation, which is becoming impressively sophisticated in terms of synthetic precision. For instance, by tuning down galvanic replacement with reducers, and optionally, the metal ions released during exchange, it is possible to coat silver nanocrystals with a few atomic layers of a more noble metal, as well as with alloy shells [99].
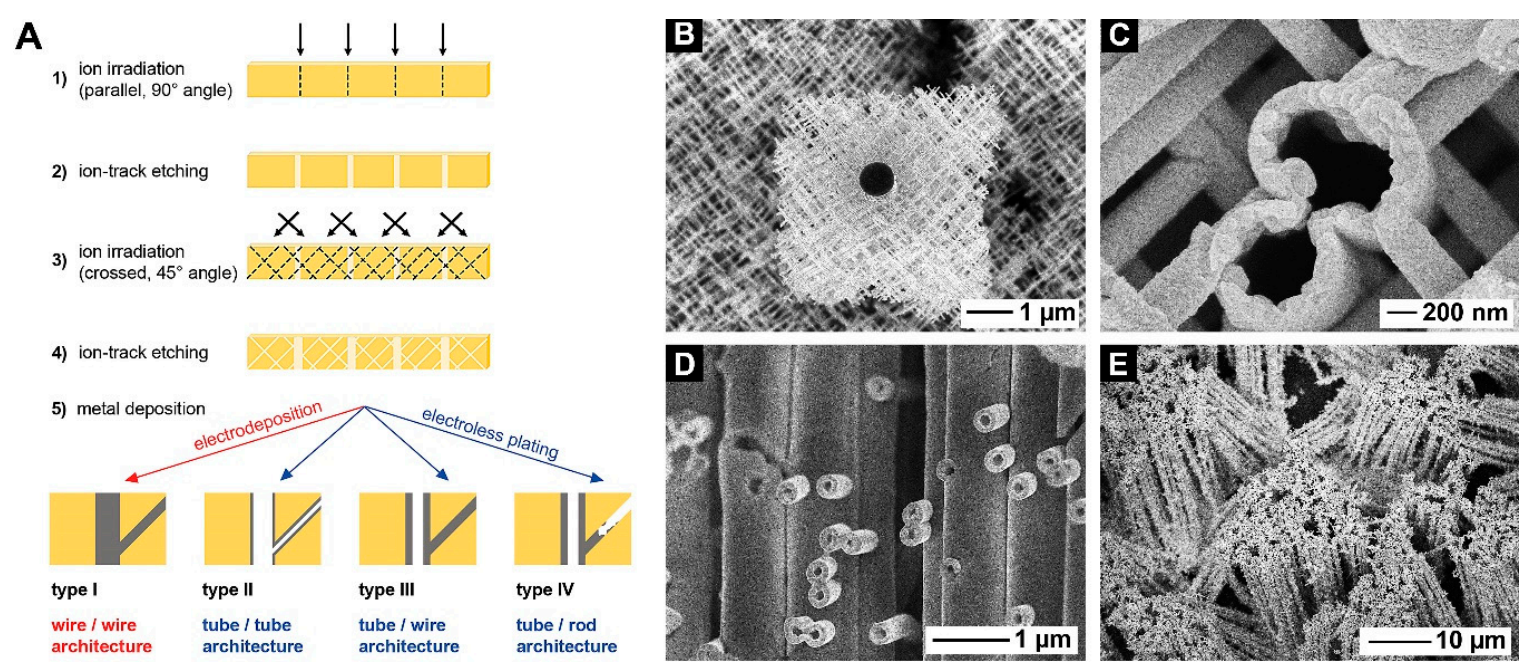

Figure 9. (A) Categorization of different nanostructures deposited in ion-track etched polymer templates of bimodal pore size. (B) Electrodeposited 3D Pt micro-/nanowire network. (C) Electrolessly plated Ag nanotube-nanowire network. (D) Electrolessly plated, hierarchical Cu nanotube-nanotube network. (E) Au nanorod-on-nanotube array, which shows aggregation due to the missing interconnection. Reprinted (adapted) with permission from [90]. Copyright (2016) Elsevier B.V.

Together with controlling the nanotube wall thickness, the introduction of porosity is an important strategy to enhance the accessibility of the interior nanotube surface $[12,65,66,71]$ and the mass activity of nanotube networks [98]. In this regard, the trade-off between the catalyst exposure, which benefits from a low thickness and high porosity of the nanotube wall, and the mechanical stability of the network, demands careful optimization. Tuning the different porosity levels is also important for the system's mass transport and for providing (nanoscale) confinement (e.g., in the nanotube interior, or in pores in the nanotube walls). The latter is important for locally concentrating intermediates, supplying nano-reactor environments, and enhancing the electrocatalytic activity/selectivity of unsupported catalysts $[100,101]$.

One fascinating aspect of 3D nanotube networks is their tri-continuous architecture, which contains two interwoven but independent pore systems which are separated by the interconnected nanotube walls and the metal surface layers deposited on the top and bottom of the former template foil. The first pore system comprises the nanotube interiors, and the second the space between the nanotubes. These pore networks could be used for constructing interlaced and conductive micro-/nanochannel systems with controlled permeation between both pore systems (depending on the tube wall porosity), if they could be independently connected within a fluidic device. Due to their hollow morphology and catalytically-active walls, metal nanotubes also represent interesting building blocks for constructing miniaturized flow reactors [67,102].

Electrodeposition is inclined to fill up the template pores starting from the bottom of an electrical contact layer on one side of the template membrane, and thus, usually yields 
3D nanowire networks (Figure $8 \mathrm{~B}-\mathrm{D}$ ), which have been prepared from different metals and metal combinations (e.g., Pt [2,90], Ni [103,104], and Ni alloys containing Fe/Co [104-106]). Crossing core-shell nanowires can be selectively etched out to obtain nanotube networks, as was demonstrated for $\mathrm{Cu}-\mathrm{Ni}$ nanocables [107]. In the case of 3D nanowire networks, the reduction of the wire diameter is critical for increasing the mass activity. Similar to the aforementioned nanotube networks, a trade-off between network stability and catalyst utilization exists: In the case of very thin nanowires, even networks with completely intact junctions begin to collapse, as the nanowires are not rigid enough to maintain a straight arrangement and a fully free-standing superstructure, which has been observed for a Pt network with a nanowires thickness of $\sim 20 \mathrm{~nm}$ [2]. Likewise to nanolattices [108], the rigidity of 3D nanotube and nanowire network catalysts can be increased by increasing their interconnectivity level, though detailed studies of the structure-dependent mechanical properties of these materials are missing so far. Reducing the forces during template removal, which is conventionally conducted by swelling and dissolving the polymer with organic solvents, followed by solvent evaporation, can also help to maintain the integrity of particularly filigree nano-networks during their release. This can be realized, e.g., by avoiding capillary effects due to supercritical drying [109] or by plasma-etching the polymer instead of dissolving it $[90,110]$. Hierarchically porous template membranes lend themselves for simultaneously optimizing different nano-network properties such as high surface area (which could be provided by a dense network of narrow nanowires) and high mechanical stability (which could be provided by larger microwires anchored within the network, Figure 9B) [90].

The outstanding structural tunability of ion-track etched membranes comes with a grain of salt. Whereas anodized alumina can be home-made in electrochemical laboratories, producing tailor-made ion-track templates requires controlled irradiation, which is only available at specific facilities (e.g., nuclear reactors, cyclotrons or linear heavy ion accelerators [81]). However, even with commercially-available ion-track etched polymer membranes, which are generally employed in filtration, nano-networks can be prepared. Intriguingly, this is enabled by a structural property which at first glance might appear as a shortcoming for nanomaterial templating: The commercial membranes contain somewhat randomly-oriented (and thus crossing) pores. At sufficiently high porosities (and thus, interconnection densities), 3D nano-networks can be deposited [63,111,112]. While the density and orientation of the pores is predefined in such membranes, they are available in different variants. Furthermore, the pore diameter can be continuously widened by simple chemical etching, which increases the likeliness of crossing pores (and in turn the nano-network stability), and provides access to fully free-standing network replicas (Figure 10) [63]. Compared to tailor-made ion-track templates optimized for nano-network fabrication, which can be created by markedly inclining the ion beam and by irradiating the polymer evenly from multiple directions, larger pore diameters are required to reach a state of efficient interconnection. Accordingly, nano-network fragmentation or collapse can be a severe issue, particularly in the case of narrow pore diameters $[113,114]$. By applying two sequential electroless plating reactions, bimetallic networks composed of core-shell nanotubes with modified composition and catalytic properties have been created (Figure 10C-E) [63].

Also, etching artefacts (similar to those found for anodized alumina $[85,86]$ ) such as the planar voids frequently found in ion-track etched polyethylene terephthalate $[92,115]$ can link the track etched channels. These voids are oriented parallel to the polymer surface, and are probably caused by biaxial stretching of the PET films, which results in a laminar structuring [115]. During etching, the etchant can penetrate through the polymer strata at some positions alongside the track etched channels, and form pores protruding from them. If the planar voids grow large enough, they can interlink multiple pores. Due to the unreliable nature of this mechanism, high porosities are required to obtain templates with reasonably interconnected pore networks in this way. 


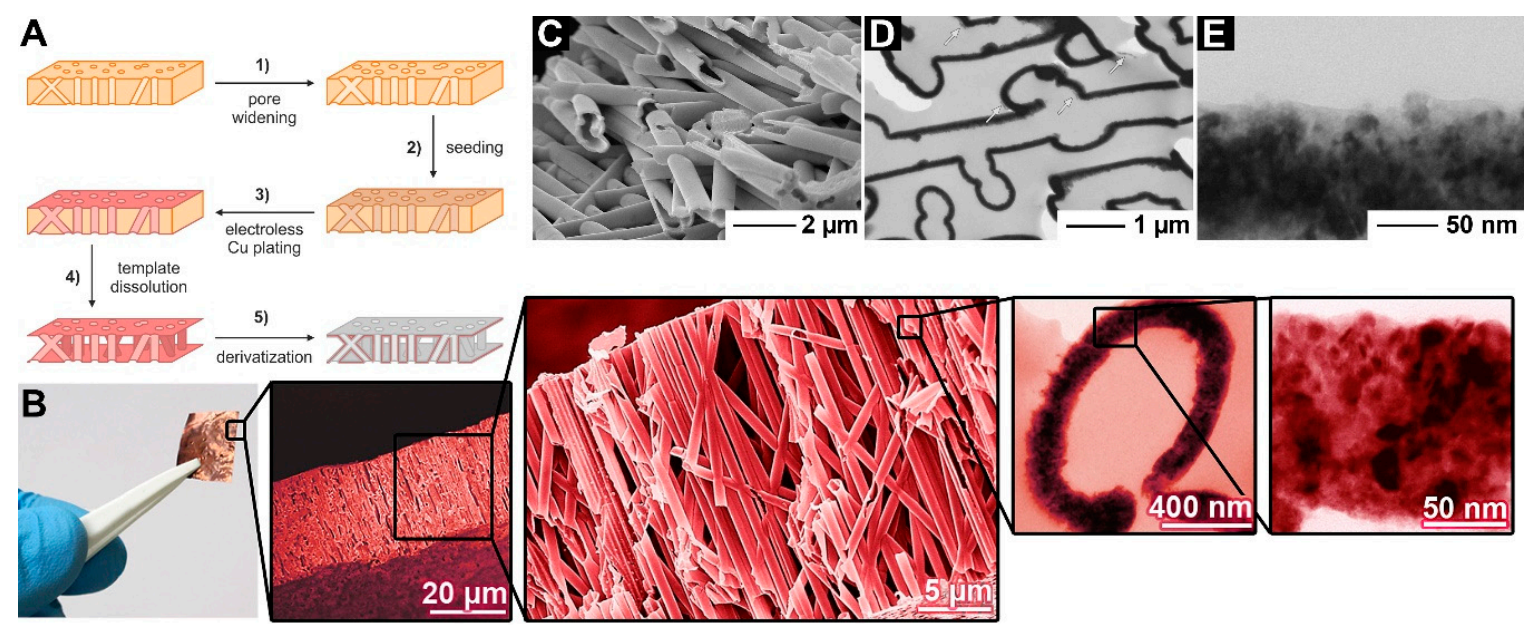

Figure 10. (A) Scheme of the deposition of 3D metal nanotube networks in commercial ion-track etched polymer membranes. (B) Collage of a photograph and false color SEM images, illustrating the multiscale architecture of a disordered $\mathrm{Cu}$ nanotube network, which ranges from the centimetre scale of the free-standing film to the tube walls composed of nanocrystalline $\mathrm{Cu}$. (C-E) Electron micrographs showing the derivatization of a Cu nanotube network with an ultrathin Ni layer, which was applied by electroless plating. Reprinted (adapted) with permission from [63]. Copyright (2016) American Chemical Society.

Due to the structural relatedness of 3D nano-networks produced in ion-track templates with the other catalyst architectures mentioned so far, it is unsurprising that they are applied in similar fields (e.g., amperometric sensors based on the catalytic conversion of electroactive species $[13,63,90$, 116], electrochemical energy conversion [2,98,111], or heterogeneous catalysis [113]). Electrochemical (bio)sensors benefit from the characteristic network architecture in a very similar way as electrocatalysts: The high activity of the latter translates into high sensitivities, which help reaching reduced detection limits $[13,63,90,116]$. In addition to providing a high density of active sites, the nanostructured surface promotes biomolecule attachment [117], and the efficient diffusive access facilitates fast sensor response $[13,66]$. Selectivity is equally important in both cases. From an instrumental perspective, the free-standing superstructure of 3D nano-networks is very much suited for integration into flow systems and microdevices. As a side note, nano-networks have also been successfully employed in chemiresistive sensing, albeit in this case, semiconductors replace the metals as the material of choice [19]. The plasmonic properties of, e.g., Au nanowire networks allow monitoring catalytic processes occurring on them with surface-enhanced Raman spectroscopy [113].

Apart from (electro)catalysis and sensing, 3D nano-networks are also valuable in related fields and can serve as miniaturized, nanostructured battery electrodes [103], which equally profit from the underlying material qualities (efficient mass transport due to high porosity and the dominance of openly accessible macropores, continuous charge collection pathways, robust superstructure, and large surface area). What makes ion-track templated nano-networks special is the structural control, including the degree of order and the high level of porosity that can be achieved. Ordered nano-networks are particularly interesting for applications which exploit properties stemming from the anisotropy and the specific mutual alignment of the 1D building blocks (e.g., magnetism [104-107]). While ion-track membranes lack the periodicity of other template variants, this aspect is far less important for constructing efficient catalysts than the ability to widely adjust the overall network architecture and porosity [118], in which they excel. This extreme structural tunability is far from being fully exhausted and translated into structure-property relationships. Also, to date, most of the ion-track templated 3D nano-networks do not utilize multimetal deposition and additional nanostructuring strategies, with which their complexity and functionality could be increased even more. 
Free-standing 3D nano-networks represent compelling materials which bridge multiple length scales: While certain —and often multiple-features of the individual building blocks remain in the nanoscale (e.g., wall thickness, crystallite size, porosity, diameter), their length is in the microscale, and the final networks can easily reach macroscopic dimensions. This makes it possible to manipulate billions of nano-objects, combined in a collective superstructure, with bare hands, and facilitates convenient device integration $[2,13,63]$. The possibility to directly grow nanostructures on patterned electrodes which have been bonded with ion-track membranes represents another great asset for device fabrication and micro-nano-integration. While this technique is often applied to the production of arrays of parallel nanostructures [119-121], it remains underutilized with respect to 3D nano-networks, apart from in a few cases $[112,116]$. Fusing the catalyst network with the electrode is superior to the attachment via binders in terms of contact quality, stability, and purity, and thus, represents an opportunity for performance enhancements.

\subsection{Nanofiber Networks Prepared by Electrospinning}

Electrospinning constitutes a scalable, template-free route toward webs composed of nanoor microfibers [122]. The fibers are ejected from droplets (mostly comprising molten or dissolved polymers) which are subjected to high voltage, causing the electrostatic repulsion of surface charges to overcome the surface tension. As a result, thin jets are drawn out, which dry or solidify during their flight to the counter electrode, and gradually build up a web-like superstructure (Figure 11A). At the beginning of fiber deposition, electrospun layers resemble 2D nano-networks [46-48], and then transition into 3D networks of increasing thickness.

While originally focusing on polymeric materials, the approach can be adjusted to produce other materials in nanofibrous form, such as oxides, carbon, metals, or their mixtures [123-125]. Metal nanowires are typically produced by adding their salts to a carrier polymer solution, which can be formulated, e.g., with poly(vinyl acetate) [126] or PVP [127]. After electrospinning, the polymer is removed by pyrolysis, which results in the formation of either oxidic (e.g., $\mathrm{CuO}$ [126], $\mathrm{Fe}_{2} \mathrm{O}_{3}$ [128], $\mathrm{CoO}$ [128] or $\mathrm{NiO}$ [128]) or metallic (e.g., $\mathrm{Pt}$ [127]) nanowires of varying purity [127], depending on the reaction conditions and the nobility of the metal. The oxidic fibers are typically transformed into metal by reduction in $\mathrm{H}_{2}$ atmosphere at elevated temperatures [126,128], but in situ reduction during application in the hydrogen evolution reaction also has been reported [129]. Also, it is possible to electrospin concentrated nanoparticle suspensions, followed by sintering, as was demonstrated for Au nanowires [130]. Metal nanotubes can be created by the two-step pyrolysis/reduction route in cases where the intermediate step yields hollow oxide nanostructures [131,132]. Alternatively, electrospun support fibers can be coated with a metal shell (e.g., using electroless plating $[46,133,134]$ or sputtering [135]), optionally followed by the isolation of the tubular products [135].

Like the closely related 3D nanotube and nanowire network catalysts, the electrospun variants are typically applied in electrochemical (bio)sensing [133], electrochemical energy conversion reactions (e.g., methanol electrooxidation [127] and oxygen reduction [131,132,136]), or water electrolysis [129], and often exhibit excellent durability [131,136]. Implementing electrospun fiber mats composed of conventional carbon-supported $\mathrm{Pt}$, ionomer, and polymer binder as fuel cell electrodes showed increased performance compared to conventional spray-coated catalyst layers, which was explained by the open-porous network architecture, its high density of accessible active sites, and its improved water management [137]. While carbon corrosion remained an issue in these nanofibers, the overall degradation of the nano-network catalyst layer was considerably reduced [137]. Optimized metallic 3D nano-networks offer the prospect of keeping the advantages of the catalyst architecture while completely circumventing the carbon corrosion problem [74]. 

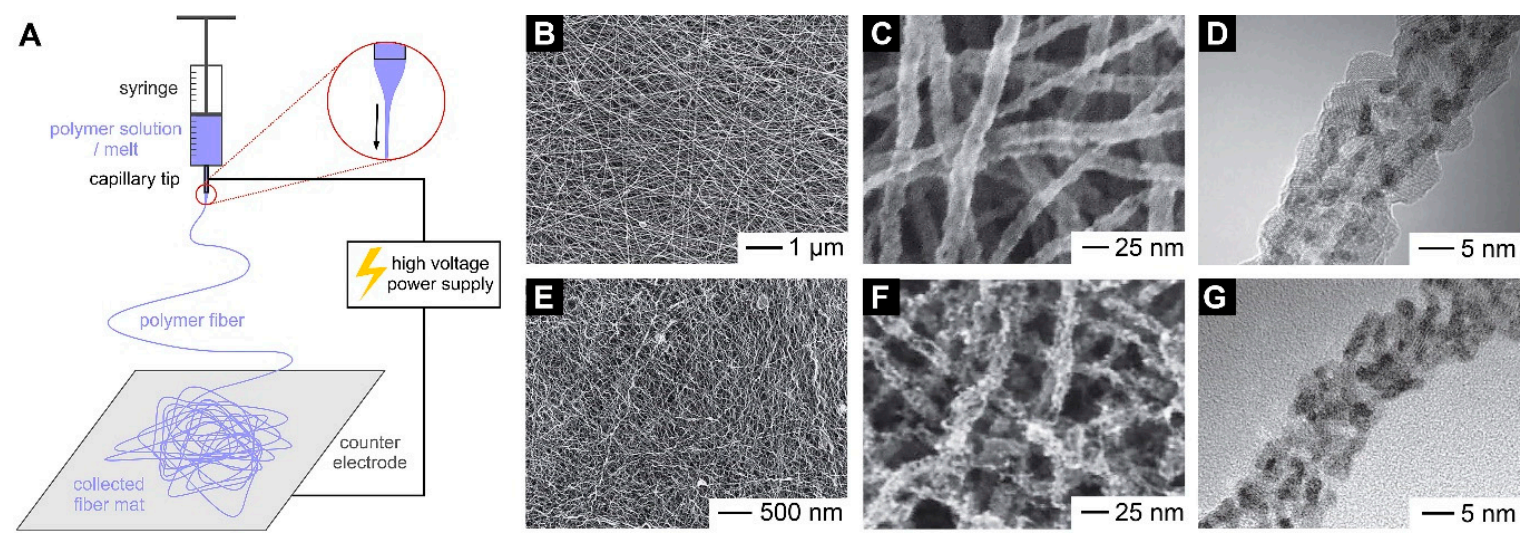

Figure 11. (A) Scheme of the fabrication of nanofiber networks with electrospinning. (B-D) Electron micrographs showing Fe-Pt nanowires, electronspun using $\mathrm{Fe}\left(\mathrm{NO}_{3}\right)_{3}$ and $\mathrm{H}_{2} \mathrm{PtCl}_{6}$ as the metal sources, followed by pyrolytic removal of the polymer carrier PVP, and reduction in $\mathrm{H}_{2}$. (E-G) Fe-depleted porous Fe-Pt alloy nanowire network obtained from the nanowires shown in (B-D) via dealloying. (B-G) Reprinted (adapted) with permission from [136]. Copyright (2011) John Wiley and Sons.

The strategies employed for improving the activity, selectivity, and metal utilization of electrospun metal catalysts relate to those outlined in the previous paragraphs. They include the creation of additional surface area (e.g., by moving from the solid nanowire to the hollow nanotube morphology [131], the introduction of pores (Figure 11B-G) $[136,138,139]$ ), improving the metal utilization by reducing the nanotube wall thickness [131] or the nanowire diameter (while avoiding bead formation [140]), and the exploitation of catalytic synergies of bimetallic or mixed oxide-metal systems $[129,131,132]$. Regarding the inclusion of metal oxides, it is important to highlight the potential value of inverse supporting for metal nano-network catalysts (i.e., the deposition of traces of a support material such as metal oxides onto an underlying metal substrate [141]). With this concept, beneficial support-metal interactions could be taken advantage of (e.g., the conservation of active metal sites or activity enhancements), while simultaneously avoiding the detriments of carbon supports.

\section{Conclusions}

Metal nanotube and nanowire networks unite a large number of desired properties, such as high surface area, porosity, stability, durability, electrical and thermal conductivity, efficient diffusive accessibility, and a high density of active sites such as grain boundaries, twin defects, or low-coordinated atoms. These properties can be efficiently controlled by adjusting their nanostructure, composition, interconnectivity, and organization, rendering nano-networks a convincing structural paradigm for designing efficient heterogeneous (electro)catalysts, nanostructured battery electrodes, or sensors.

The discussed fabrication strategies show a general trade-off between synthetic precision and process intricacy. While template-guided metal depositions make it possible to exert a stunning level of direct control over the network architecture, they rely on complex multistep procedures. On the other hand, the colloidal synthesis of nanowire suspensions can be scaled up quite easily, but the superstructures assembled from these building blocks show much more randomness and a poor initial interconnection quality. Thus, it is anticipated that the more powerful but also laborious techniques will find preferential use in high performance applications and fields which do not require large amounts of material (e.g., sensors or lab-on-a-chip devices), as well as for investigating structure-property relationships and identifying particularly efficient nano-network variants. This knowledge can then serve as a basis for creating catalysts for cost-sensitive large-scale applications, such as fuel cells, with more readily scalable approaches such as electrospinning.

In this regard, although very promising results have been obtained in the individual half-cell reactions, it continues to be difficult to implement nano-network catalysts in membrane electrode 
assemblies and test them under realistic operation conditions, despite the great potential which lies in their unique architecture. It is particularly in fields such as achieving high metal loadings (and thus raw power), high surface-normalized activity, high and open porosity, and excellent durability that nano-network catalysts can play out their strengths. It is not simple to beat conventional carbon-supported Pt electrocatalysts in terms of noble metal utilization-a task for which they have been thoroughly optimized. Nonetheless, this can be achieved through careful nano- and microstructural tuning. It is not surprising that a proper integration of nano-network catalysts into fuel cells, and the issues associated with aspects like catalyst attachment to the membrane, ionomer application, adaption of the water management, will require similar efforts on larger length scales [74]. Likewise, the assembly of nano-networks into flow reactors [142] and miniaturized devices [143], for which their free-standing superstructure is predestined, provides plentiful challenges and opportunities for catalysis research.

Supplementary Materials: The following are available online at http:/ / www.mdpi.com/2073-4344/8/12/597/s1, Table S1. Summary of the nano-network examples discussed in Section 2.1 (2D nano-networks, preparation from colloidal building blocks). Table S2. Summary of the nano-network examples discussed in Section 2.2 (2D nano-networks, template-assisted deposition). Table S3. Summary of the nano-network examples discussed in Section 3.1 (3D nano-networks, preparation from individual 1D nanostructures). Table S4. Summary of the nano-network examples discussed in Section 3.2 (3D nano-networks, template-assisted deposition). Table S5. Summary of the nano-network examples discussed in Section 3.3 (3D nano-networks, nanofiber networks prepared by electrospinning).

Funding: This research received no external funding.

Acknowledgments: F. M. thanks all his co-workers from the Technische Universität Darmstadt (Germany) and the Weizmann Institute of Science (Israel), who contributed to the research on anisotropic metal nano-objects, their superstructures and (electro)catalytic application. This body of work laid the foundation for writing this review.

Conflicts of Interest: The author declares no conflict of interest.

\section{References}

1. Schulenberg, H.; Schwanitz, B.; Linse, N.; Scherer, G.G.; Wokaun, A. 3D Imaging of Catalyst Support Corrosion in Polymer Electrolyte Fuel Cells. J. Phys. Chem. C 2011, 115, 14236-14243. [CrossRef]

2. Rauber, M.; Alber, I.; Müller, S.; Neumann, R.; Picht, O.; Roth, C.; Schökel, A.; Toimil-Molares, M.E.; Ensinger, W. Highly-Ordered Supportless Three-Dimensional Nanowire Networks with Tunable Complexity and Interwire Connectivity for Device Integration. Nano Lett. 2011, 11, 2304-2310. [CrossRef] [PubMed]

3. Choi, S.M.; Kim, J.H.; Jung, J.Y.; Yoon, E.Y.; Kim, W.B. Pt nanowires prepared via a polymer template method: Its promise toward high Pt-loaded electrocatalysts for methanol oxidation. Electrochim. Acta 2008, 53, 5804-5811. [CrossRef]

4. Du, L.; Shao, Y.; Sun, J.; Yin, G.; Liu, J.; Wang, Y. Advanced catalyst supports for PEM fuel cell cathodes. Nano Energy 2016, 29, 314-322. [CrossRef]

5. Setzler, B.P.; Zhuang, Z.; Wittkopf, J.A.; Yan, Y. Activity targets for nanostructured platinum-group-metal-free catalysts in hydroxide exchange membrane fuel cells. Nat. Nanotechnol. 2016, 11, 1020-1025. [CrossRef] [PubMed]

6. Cai, B.; Henning, S.; Herranz, J.H.; Schmidt, T.J.; Eychmüller, A. Nanostructuring Noble Metals as Unsupported Electrocatalysts for Polymer Electrolyte Fuel Cells. Adv. Energy Mater. 2017, 7, 1700548. [CrossRef]

7. Tian, X.L.; Xu, Y.Y.; Zhang, W.; Wu, T.; Xia, B.Y.; Wang, X. Unsupported Platinum-Based Electrocatalysts for Oxygen Reduction Reaction. ACS Energy Lett. 2017, 2, 2035-2043. [CrossRef]

8. Antolini, W.; Perez, J. The renaissance of unsupported nanostructured catalysts for low-temperature fuel cells: From the size to the shape of metal nanostructures. J. Mater. Sci. 2011, 46, 4435-4457. [CrossRef]

9. Koenigsmann, C.; Wong, S.S. One-dimensional noble metal electrocatalysts: A promising structural paradigm for direct methanol fuel cells. Energy Environ. Sci. 2011, 4, 1161-1176. [CrossRef] 
10. Koenigsmann, C.; Scofield, M.E.; Liu, H.; Wong, S. Designing Enhanced One-Dimensional Electrocatalysts for the Oxygen Reduction Reaction: Probing Size- and Composition-Dependent Electrocatalytic Behavior in Noble Metal Nanowires. J. Phys. Chem. Lett. 2012, 3, 3385-3398. [CrossRef]

11. Chen, Z.; Waje, M.; Li, W.; Yan, Y. Supportless Pt and PtPd Nanotubes as Electrocatalysts for Oxygen Reduction Reactions. Angew. Chem. Int. Ed. 2007, 46, 4060-4063. [CrossRef] [PubMed]

12. Alia, S.M.; Zhang, G.; Kisailus, D.; Li, D.; Gu, S.; Jensen, K.; Yan, Y. Porous Platinum Nanotubes for Oxygen Reduction and Methanol Oxidation Reactions. Adv. Funct. Mater. 2010, 20, 3742-3746. [CrossRef]

13. Muench, F.; De Carolis, D.M.; Felix, E.-M.; Brötz, J.; Kunz, U.; Kleebe, H.-J.; Ayata, S.; Trautmann, C.; Ensinger, W. Self-Supporting Metal Nanotube Networks Obtained by Highly Conformal Electroless Plating. ChemPlusChem 2015, 80, 1448-1456. [CrossRef]

14. Ni, C.-J.; Hong, F.C.-N. Electroless nanowelding of silver nanowires at room temperature. RSC Adv. 2014, 4, 40330-40338. [CrossRef]

15. Romo-Herrera, J.M.; Terrones, M.; Terrones, H.; Dag, S.; Meunier, V. Covalent 2D and 3D Networks from 1D Nanostructures: Designing New Materials. Nano Lett. 2007, 7, 570-576. [CrossRef]

16. Zhao, X.; Muench, F.; Schaefer, S.; Fasel, C.; Kunz, U.; Ayata, S.; Liu, S.; Kleebe, H.-J.; Ensinger, W. Carbon nanocasting in ion-track etched polycarbonate membranes. Mater. Lett. 2017, 187, 56-59. [CrossRef]

17. Movsesyan, L.; Schubert, I.; Yeranyan, L.; Trautmann, C.; Toimil-Molares, M.-E. Influence of electrodeposition parameters on the structure and morphology of $\mathrm{ZnO}$ nanowire arrays and networks synthesized in etched ion-track membranes. Semicond. Sci. Technol. 2016, 31, 014006. [CrossRef]

18. Wagner, M.F.P.; Völklein, F.; Reith, H.; Trautmann, C.; Toimil-Molares, M.-E. Fabrication and thermoelectrical characterization of three-dimensional nanowire networks. Phys. Status Solidi A 2016, 213, 610-619. [CrossRef]

19. Piraux, L.; Antohe, V.-A.; Ferain, E.; Lahem, D. Self-supported three-dimensionally interconnected polypyrrole nanotubes and nanowires for highly sensitive chemiresistive gas sensing. RSC Adv. 2016, 6, 21808-21813. [CrossRef]

20. Li, G.G.; Wang, H. Dealloyed Nanoporous Gold Catalysts: From Macroscopic Foams to Nanoparticulate Architectures. ChemNanoMat 2018, 4, 897-908. [CrossRef]

21. Fouilloux, P. The nature of raney nickel, its adsorbed hydrogen and its catalytic activity for hydrogenation reactions. Appl. Catal. 1983, 8, 1-42. [CrossRef]

22. Ron, R.; Haleva, E.; Salomon, A. Nanoporous Metallic Networks: Fabrication, Optical Properties, and Applications. Adv. Mater. 2018, 30, 1706755. [CrossRef] [PubMed]

23. Cui, J.; Zhang, H.; Yu, Y.; Liu, Y.; Tian, Y.; Zhang, B. Synergism of interparticle electrostatic repulsion modulation and heat-induced fusion: A generalized one-step approach to porous network-like noble metals and their alloy nanostructures. J. Mater. Chem. 2012, 22, 349-354. [CrossRef]

24. Wang, M.-H.; Li, Y.-L.; Xie, Z.-X.; Liu, C.; Yeung, E.S. Fabrication of large-scale one-dimensional Au nanochain and nanowire networks by interfacial self-assembly. Mater. Chem. Phys. 2010, 119, 153-157. [CrossRef]

25. Ruan, L.; Zhu, E.; Chen, Y.; Lin, Z.; Huang, X.; Duan, X.; Huang, Y. Biomimetic Synthesis of an Ultrathin Platinum Nanowire Network with a High Twin Density for Enhanced Electrocatalytic Activity and Durability. Angew. Chem. Int. Ed. 2013, 52, 12577-12581. [CrossRef] [PubMed]

26. McCue, I.; Benn, E.; Gaskey, B.; Erlebacher, J. Dealloying and Dealloyed Materials. Annu. Rev. Mater. Res. 2016, 46, 263-286. [CrossRef]

27. Zhu, C.; Du, D.; Eychmüller, A.; Lin, Y. Engineering Ordered and Nonordered Porous Noble Metal Nanostructures: Synthesis, Assembly, and Their Applications in Electrochemistry. Chem. Rev. 2015, 115, 8896-8943. [CrossRef]

28. Liu, W.; Herrmann, A.-K.; Bigall, N.C.; Rodriguez, P.; Wen, D.; Oezaslan, M.; Schmidt, T.J.; Gaponik, N.; Eychmüller, A. Noble Metal Aerogels-Synthesis, Characterization, and Application as Electrocatalysts. Acc. Chem. Res. 2015, 48, 154-162. [CrossRef]

29. Ye, S.; Rathmell, A.R.; Chen, Z.; Stewart, I.E.; Wiley, B.J. Metal Nanowire Networks: The Next Generation of Transparent Conductors. Adv. Mater. 2014, 26, 6670-6687. [CrossRef]

30. Shi, H.-Y.; Hu, B.; Yu, X.-C.; Zhao, R.-L.; Ren, X.-F.; Liu, S.-L.; Liu, J.-W.; Feng, M.; Xu, A.-W.; Yu, A.-H. Ordering of Disordered Nanowires: Spontaneous Formation of Highly Aligned, Ultralong Ag Nanowire Films at Oil-Water-Air Interface. Adv. Funct. Mater. 2010, 20, 958-964. [CrossRef]

31. Sun, Y.; Mayers, B.; Herricks, T.; Xia, Y. Polyol Snythesis of Uniform Silver Nanowires: A Plausible Growth Mechanism and the Supporting Evidence. Nano Lett. 2003, 3, 955-960. [CrossRef] 
32. Huang, H.; Ruditskiy, A.; Choi, S.-I.; Zhang, L.; Liu, J.; Ye, Z.; Xia, Y. One-Pot Synthesis of Penta-twinned Palladium Nanowires and Their Enhanced Electrocatalytic Properties. ACS Appl. Mater. Interfaces 2017, 9, 31203-31212. [CrossRef]

33. Liu, X.; Wu, N.; Wunsch, B.H.; Barsotti, R.J., Jr.; Stellacci, F. Shape-Controlled Growth of Micrometer-Sized Gold Crystals by a Slow Reduction Method. Small 2006, 2, 1046-1050. [CrossRef] [PubMed]

34. Yang, L.; Zhang, Y.; Chu, M.; Deng, W.; Tan, Y.; Ma, M.; Su, X.; Xie, Q.; Yao, S. Facile fabrication of network film electrodes with ultrathin nanowires for nonenzymatic glucose sensing and glucose $/ \mathrm{O}_{2}$ fuel cell. Biosens. Bioelectron. 2014, 52, 105-110. [CrossRef] [PubMed]

35. Xia, B.Y.; Wu, H.B.; Yan, Y.; Lou, X.W.; Wang, X. Ultrathin and Ultralong Singe-Crystal Platinum Nanowire Assemblies with Highly Stable Electrocatalytic Activity. J. Am. Chem. Soc. 2013, 135, 9480-9485. [CrossRef]

36. Kang, H.; Kim, Y.; Cheon, S.; Yi, G.-R.; Cho, J.H. Halide Welding for Silver Nanowire Network Electrode. ACS Appl. Mater. Interfaces 2017, 9, 30779-30785. [CrossRef] [PubMed]

37. Garnett, E.C.; Cai, W.; Cha, J.J.; Mahmood, F.; Connor, S.T.; Christoforo, M.G.; Cui, Y.; McHegee, M.D.; Brongersma, M.L. Self-limited plasmonic welding of silver nanowire junctions. Nat. Mater. 2012, 11, $241-249$. [CrossRef]

38. Tokuno, T.; Nogi, M.; Karakawa, M.; Jiu, J.; Nge, T.T.; Aso, Y.; Suganuma, K. Fabrication of Silver Nanowire Transparent Electrodes at Room Temperature. Nano Res. 2011, 4, 1215-1222. [CrossRef]

39. Lee, J.H.; Huynh-Nguyen, B.-C.; Ko, E.; Kim, J.H.; Seong, G.H. Fabrication of flexible, transparent silver nanowire electrodes for amperometric detection of hydrogen peroxide. Sens. Actuators B Chem. 2016, 224, 789-797. [CrossRef]

40. Manikandan, A.; Lee, L.; Wang, Y.-C.; Chen, C.-W.; Chen, Y.-Z.; Medina, H.; Tseng, J.-Y.; Wang, Z.M.; Chueh, Y.-L. Graphene-coated copper nanowire networks as a highly stable transparent electrode in harsh environments toward efficient electrocatalytic hydrogen evolution reactions. J. Mater. Chem. A 2017, 5, 13320-13328. [CrossRef]

41. Chen, Z.; Ye, S.; Wilson, A.R.; Ha, Y.-C.; Wiley, B.J. Optically transparent hydrogen evolution catalysts made from networks of copper-platinum core-shell nanowires. Energy Environ. Sci. 2014, 7, 1461-1467. [CrossRef]

42. Ge, J.; Wei, P.; Wu, G.; Liu, Y.; Yuan, T.; Li, Z.; Qu, Y.; Wu, Y.; Li, H.; Zhuang, Z.; et al. Ultrathin Palladium Nanomesh for Electrocatalysis. Angew. Chem. Int. Ed. 2018, 57, 3435-3438. [CrossRef] [PubMed]

43. Bakar, N.A.; Shapter, J.G.; Salleh, M.M.; Umar, A.A. Self-Assembly of High Density of Triangular Silver Nanoplate Films Promoted by 3-Aminopropyltrimethoxysilane. Appl. Sci. 2015, 5, 209-221. [CrossRef]

44. Muench, F.; Popovitz-Biro, R.; Bendikov, T.; Feldman, Y.; Hecker, B.; Oezaslan, M.; Rubinstein, I.; Vaskevich, A. Nucleation-Controlled Solution Deposition of Silver Nanoplate Architectures for Facile Derivatization and Catalytic Applications. Adv. Mater. 2018, 1805179. [CrossRef]

45. Zeng, X.Q.; Latimer, M.L.; Xiao, Z.L.; Panuganti, S.; Welp, U.; Kwok, W.K.; Xu, T. Hydrogen Gas Sensing with Networks of Ultrasmall Palladium Nanowires Formed on Filtration Membranes. Nano Lett. 2011, 11, 262-268. [CrossRef] [PubMed]

46. Hsu, P.-C.; Kong, D.; Wang, S.; Wang, H.; Welch, A.J.; Wu, H.; Cui, Y. Electrolessly Deposited Electrospun Metal Nanowire Transparent Electrodes. J. Am. Chem. Soc. 2014, 136, 10593-10596. [CrossRef] [PubMed]

47. Wu, H.; Kong, D.; Ruan, Z.; Hsu, P.-C.; Wang, S.; Yu, Z.; Carney, T.J.; Hu, L.; Fan, S.; Cui, Y. A transparent electrode based on a metal nanotrough network. Nat. Nanotechnol. 2013, 8, 421-425. [CrossRef] [PubMed]

48. Kim, J.; Kang, J.; Jeong, U.; Kim, H.; Lee, H. Catalytic, Conductive, and Transparent Platinum Nanofiber Webs for FTO-Free Dye-Sensitized Solar Cells. ACS Appl. Mater. Interfaces 2013, 5, 3176-3181. [CrossRef] [PubMed]

49. Guo, C.F.; Sun, T.; Liu, Q.; Suo, Z.; Ren, Z. Highly stretchable and transparent nanomesh electrodes made by grain boundary lithography. Nat. Commun. 2014, 5, 3121. [CrossRef] [PubMed]

50. Ibbotson, L.A.; Demetriadou, A.; Croxall, S.; Hess, O.; Baumberg, J.J. Optical nano-woodpiles: Large-area metallic photonic crystals and metamaterials. Sci. Rep. 2015, 5, 8313. [CrossRef]

51. Zhang, Y.; Su, L.; Manuzzi, D.; de los Monteros, H.V.E.; Jia, W.; Huo, D.; Hou, C.; Lei, Y. Ultrasensitive and selective non-enzymatic glucose detection using copper nanowires. Biosens. Bioelectron. 2012, 31, 426-432. [CrossRef] [PubMed]

52. Xu, Y.; Chu, Z.; Shi, L.; Peng, J.; Jin, W. Prussian blue nanocubes decorated three-dimensional silver nanowires network for high-performance electrochemical biosensing. Sens. Actuators B Chem. 2015, 221, 1009-1016. [CrossRef] 
53. Xi, W.; Ma, R.; Wang, H.; Gao, Z.; Zhang, W.; Zhao, Y. Ultrathin Ag Nanowire Electrode for Electrochemical Syngas Production from Carbon Dioxide. ACS Sustain. Chem. Eng. 2018, 6, 7687-7694. [CrossRef]

54. Wang, C.; Zhang, Z.; Yang, G.; Chen, Q.; Yin, Y.; Jin, M. Creation of Controllable High-Density Defects in Silver Nanowires for Enhanced Catalytic Property. Nano Lett. 2016, 16, 5669-5674. [CrossRef]

55. Bi, Y.; Lu, G. Control growth of uniform platinum nanotubes and their catalytic properties for methanol electrooxidation. Electrochem. Commun. 2009, 11, 45-49. [CrossRef]

56. Alia, S.M.; Jensen, K.O.; Pivovar, B.S.; Yan, Y. Platinum-Coated Palladium Nanotubes as Oxygen Reduction Reaction Electrocatalysts. ACS Catal. 2012, 2, 858-863. [CrossRef]

57. Su, L.; Shrestha, S.; Zhang, Z.; Mustain, W.; Lei, Y. Platinum-copper nanotube electrocatalyst with enhanced activity and durability for oxygen reduction reactions. J. Mater. Chem. A 2013, 1, 12293-12301. [CrossRef]

58. Alia, S.M.; Duong, K.; Liu, T.; Jensen, K.; Yan, Y. Palladium and Gold Nanotubes as Oxygen Reduction Reaction and Alcohol Oxidation Reaction Catalysts in Base. ChemSusChem 2014, 7, 1739-1744. [CrossRef] [PubMed]

59. Lu, C.; Kong, W.; Zhang, H.; Song, B.; Wang, Z. Gold-platinum bimetallic nanotubes templated from tellurium nanowires as efficient electrocatalysts for methanol oxidation reaction. J. Power Sources 2015, 296, 102-108. [CrossRef]

60. Zheng, J.; Cullen, D.A.; Forest, R.V.; Wittkopf, J.A.; Zhuang, Z.; Sheng, W.; Chen, J.G.; Yan, Y. Platinum-Ruthenium Nanotubes and Platinum-Ruthenium Coated Copper Nanowires As Efficient Catalysts for Electro-Oxidation of Methanol. ACS Catal. 2015, 5, 1468-1474. [CrossRef]

61. Schaefer, S.; Muench, F.; Mankel, E.; Fuchs, A.; Brötz, J.; Kunz, U.; Ensinger, W. Double-Walled Ag-Pt Nanotubes Fabricated by Galvanic Replacement and Dealloying: Effect of Composition on the Methanol Oxidation Activity. Nano 2015, 10, 1550085. [CrossRef]

62. Xia, Y.; Sun, Y. Multiple-Walled Nanotubes Made of Metals. Adv. Mater. 2004, 16, 264-268. [CrossRef]

63. Muench, F.; Sun, L.; Kottakkat, T.; Antoni, M.; Schaefer, S.; Kunz, U.; Molina-Luna, L.; Duerrschnabel, M.; Kleebe, H.-J.; Ayata, S.; et al. Free-Standing Networks of Core-Shell Metal and Metal Oxide Nanotubes for Glucose Sensing. ACS Appl. Mater. Interfaces 2017, 9, 771-781. [CrossRef] [PubMed]

64. Muench, F.; Kaserer, S.; Kunz, U.; Svoboda, I.; Brötz, J.; Lauterbach, S.; Kleebe, H.-J.; Roth, C.; Ensinger, W. Electroless synthesis of platinum and platinum-ruthenium nanotubes and their application in methanol oxidation. J. Mater. Chem. 2011, 21, 6286-6291. [CrossRef]

65. Muench, F.; Neetzel, C.; Kaserer, S.; Brötz, J.; Jaud, J.-C.; Zhao-Karger, Z.; Lauterbach, S.; Kleebe, H.-J.; Roth, C.; Ensinger, W. Fabrication of porous rhodium nanotube catalysts by electroless plating. J. Mater. Chem. 2012, 22, 12784-12791. [CrossRef]

66. Felix, E.-M.; Muench, F.; Ensinger, W. Green plating of high aspect ratio gold nanotubes and their morphology-dependent performance in enzyme-free peroxide sensing. RSC Adv. 2014, 4, 24504-24510. [CrossRef]

67. Muench, F.; Rauber, M.; Stegmann, C.; Lauterbach, S.; Kunz, E.; Kleebe, H.-J.; Ensinger, W. Ligand-optimized electroless synthesis of silver nanotubes and their activity in the reduction of 4-nitrophenol. Nanotechnology 2011, 22, 415602. [CrossRef] [PubMed]

68. Atkinson, R.W., III; Unocic, R.R.; Unocic, K.A.; Veith, G.M.; Zawodzinski, T.A., Jr.; Papandrew, A.B. Vapor Synthesis and Thermal Modification of Supportless Platinum-Ruthenium Nanotubes and Application as Methanol Electrooxidation Catalysts. ACS Appl. Mater. Interfaces 2015, 7, 10115-10124. [CrossRef]

69. Bechelany, M.; Chaaya, A.A.; Frances, F.; Akdim, O.; Cot, D.; Demirci, U.B.; Miele, P. Nanowires with controlled porosity for hydrogen production. J. Mater. Chem. A 2013, 1, 2133-2138. [CrossRef]

70. Yamauchi, Y.; Takai, A.; Nagaura, T.; Inoue, S.; Kuroda, K. Pt Fibers with Stacked Donut-Like Mesospace by Assembling Pt Nanoparticles: Guided Deposition in Physically Confined Self-Assembly of Surfactants. J. Am. Chem. Soc. 2008, 130, 5426-5427. [CrossRef]

71. Muench, F.; Schaefer, S.; Hagelüken, L.; Molina-Luna, L.; Duerrschnabel, M.; Kleebe, H.-J.; Brötz, J.; Vaskevich, A.; Rubinstein, I.; Ensinger, W. Template-Free Electroless Plating of Gold Nanowires: Direct Surface Functionalization with Shape-Selective Nanostructures for Electrochemical Applications. ACS Appl. Mater. Interfaces 2017, 9, 31142-31152. [CrossRef] [PubMed]

72. Cui, C.-H.; Li, H.-H.; Yu, J.-W.; Gao, M.-R.; Yu, S.-H. Ternary Heterostructured Nanoparticle Tubes: A Dual Catalyst and Its Synergistic Enhancement Effects for $\mathrm{O}_{2} / \mathrm{H}_{2} \mathrm{O}_{2}$ Reduction. Angew. Chem. Int. Ed. 2010, 49, 9149-9152. [CrossRef] [PubMed] 
73. Lee, W.; Scholz, R.; Nielsch, K.; Gösele, U. A Template-Based Electrochemical Method for the Synthesis of Multisegmented Metallic Nanotubes. Angew. Chem. Int. Ed. 2005, 44, 6050-6054. [CrossRef] [PubMed]

74. Mauger, S.A.; Neyerlin, K.C.; Alia, S.M.; Ngo, C.; Babu, S.K.; Hurst, K.E.; Pylypenko, S.; Lister, S.; Pivovar, B.S. Fuel Cell Performance Implications of Membrane Electrode Assembly Fabrication with Platinum-Nickel Nanowire Catalysts. J. Electrochem. Soc. 2018, 165, F238-F245. [CrossRef]

75. Jung, S.M.; Jung, H.Y.; Dresselhaus, M.S.; Jung, Y.J.; Kong, J. A facile route for 3D aerogels from nanostructured 1D and 2D materials. Sci. Rep. 2012, 2, 849. [CrossRef] [PubMed]

76. Jung, S.M.; Preston, D.J.; Jung, H.Y.; Deng, Z.; Wang, E.N.; Kong, J. Porous Cu Nanowire Aerosponges from One-Step Assembly and their Applications in Heat Dissipation. Adv. Mater. 2016, 28, 1413-1419. [CrossRef]

77. Gilbert, D.A.; Burks, E.C.; Ushakov, S.V.; Abellan, P.; Arslan, I.; Felter, T.E.; Navrotsky, A.; Liu, K. Tunable Low Density Palladium Nanowire Foams. Chem. Mater. 2017, 29, 9814-9818. [CrossRef]

78. Li, Z.; Leung, C.; Gao, F.; Gu, Z. Effects of Nanowire Length and Surface Roughness on the Electrochemical Sensor Properties of Nafion-Free, Vertically Aligned Pt Nanowire Array Electrodes. Sensors 2015, 15, 22473-22489. [CrossRef]

79. Jani, A.M.M.; Losic, D.; Voelcker, N.H. Nanoporous anodic aluminium oxide: Advances in surface engineering and emerging applications. Progr. Mater. Sci. 2013, 58, 636-704. [CrossRef]

80. Martin, C.R. Nanomaterials: A Membrane-Based Synthetic Approach. Science 1994, 266, 1961-1966. [CrossRef]

81. Apel, P. Track etching technique in membrane technology. Radiat. Meas. 2001, 34, 559-566. [CrossRef]

82. Bayat, H.; Lin, C.-H.; Cheng, M.-H.; Steuber, M.; Chen, J.-T.; Schönherr, H. Interplay of Template Constraints and Microphase Separation in Polymeric Nano-Objects Replicated from Novel Modulated and Interconnected Nanoporous Anodic Alumina. ACS Appl. Nano Mater. 2018, 1, 200-208. [CrossRef]

83. Martín, J.; Martín-González, M.; Fernández, J.F.; Caballero-Calero, O. Ordered three-dimensional interconnected nanoarchitectures in anodic porous alumina. Nat. Commun. 2014, 5, 5130. [CrossRef] [PubMed]

84. Vanpaemel, J.; Abd-Elnaiem, A.M.; De Gendt, S.; Vereecken, P.M. The Formation Mechanism of 3D Porous Anodized Aluminum Oxide Templates from an Aluminum Film with Copper Impurities. J. Phys. Chem. C 2015, 119, 2105-2112. [CrossRef]

85. Tian, M.; Wang, W.; Wei, Y.; Yang, R. Stable high areal capacity lithium-ion battery anodes based on three-dimensional Ni-Sn nanowire networks. J. Power Sources 2012, 211, 46-51. [CrossRef]

86. Mebed, A.M.; Abd-Elnaiem, A.M.; Al-Hosiny, N.M. Electrochemical fabrication of 2D and 3D nickel nanowires using porous anodic alumina templates. Appl. Phys. A 2016, 122, 565. [CrossRef]

87. Guo, F.; Li, Y.; Fan, B.; Liu, Y.; Lu, L.; Lei, Y. Carbon- and Binder-Free Core-Shell Nanowire Arrays for Efficient Ethanol Electro-Oxidation in Alkaline Medium. ACS Appl. Mater. Interfaces 2018, 10, 4705-4714. [CrossRef]

88. Luan, C.; Shao, Y.; Lu, Q.; Gao, S.; Huang, K.; Wu, H.; Yao, K. High-Performance Carbon Dioxide Electrocatalytic Reduction by Easily Fabricated Large-Scale Silver Nanowire Arrays. ACS Appl. Mater. Interfaces 2018, 10, 17950-17956. [CrossRef]

89. Kim, H.J.; Kim, Y.S.; Seo, M.H.; Choi, S.M.; Cho, J.; Huber, G.W.; Kim, W.B. Highly improved oxygen reduction performance over $\mathrm{Pt} / \mathrm{C}$-dispersed nanowire network catalysts. Electrochem. Commun. 2010, 12, 32-35. [CrossRef]

90. Muench, F.; Felix, E.-M.; Rauber, M.; Schaefer, S.; Antoni, M.; Kunz, U.; Kleebe, H.-J.; Trautmann, C.; Ensinger, W. Electrodeposition and electroless plating of hierarchical metal superstructures composed of 1D nano- and microscale building blocks. Electrochim. Acta 2016, 202, 47-54. [CrossRef]

91. Muench, F.; Kunz, U.; Wardenga, H.F.; Kleebe, H.-J.; Ensinger, W. Metal Nanotubes and Nanowires with Rhombohedral Cross-Section Electrolessly Deposited in Mica Templates. Langmuir 2014, 30, 10878-10885. [CrossRef] [PubMed]

92. Muench, F.; Oezaslan, M.; Rauber, M.; Kaserer, S.; Fuchs, A.; Mankel, E.; Brötz, J.; Strasser, P.; Roth, C.; Ensinger, W. Electroless synthesis of nanostructured nickel and nickel-boron tubes and their performance as unsupported ethanol electrooxidation catalysts. J. Power Sources 2013, 222, 243-252. [CrossRef]

93. Didyk, A.Y.; Dmitriev, S.N.; Vutsadakis, W. Spatial Overlapping of Holes in Nuclear-Track Membranes with Different Angular Distributions. High Energy Chem. 2003, 37, 121-127. [CrossRef] 
94. Wei, X.; Roper, D.K. Tin Sensitization for Electroless Plating Review. J. Electrochem. Soc. 2014, 161, D235-D242. [CrossRef]

95. Muench, F.; Eils, A.; Toimil-Molares, M.E.; Hossain, U.H.; Radetinac, A.; Stegmann, C.; Kunz, U.; Lauterbach, S.; Kleebe, H.-J.; Ensinger, W. Polymer activation by reducing agent absorption as a flexible tool for the creation of metal films and nanostructures by electroless plating. Surf. Coat. Technol. 2014, 242, 100-108. [CrossRef]

96. Korolkov, I.V.; Borgekov, D.B.; Mashentseva, A.A.; Güven, O.; Atici, A.B.; Kozlovskiy, A.L.; Zdorovets, M.V. The effect of oxidation pretreatment of polymer template on the formation and catalytic activity of Au/PET membrane composites. Chem. Pap. 2017, 71, 2353-2358. [CrossRef]

97. Schaefer, S.; Felix, E.-M.; Muench, F.; Antoni, M.; Lohaus, C.; Brötz, J.; Kunz, U.; Gärtner, I.; Ensinger, W. NiCo nanotubes plated on Pd seeds as designed magnetically recollectable catalysts with high noble metal utilization. RSC Adv. 2016, 6, 70033-70039. [CrossRef]

98. Walbert, T.; Antoni, M.; Muench, F.; Späth, T.; Ensinger, W. Electroless Synthesis of Highly Stable and Free-Standing Porous Pt Nanotube Networks and their Application in Methanol Oxidation. ChemElectroChem 2018, 5, 1087-1097. [CrossRef]

99. Wu, Y.; Sun, X.; Yang, Y.; Li, J.; Zhang, Y.; Qin, D. Enriching Silver Nanocrystals with a Second Noble Metal. Acc. Chem. Res. 2017, 50, 1774-1784. [CrossRef] [PubMed]

100. Yoon, Y.; Hall, A.S.; Surendranath, Y. Tuning of Silver Catalyst Mesostructure Promotes Selective Carbon Dioxide Conversion into Fuels. Angew. Chem. Int. Ed. 2016, 55, 15282-15286. [CrossRef]

101. Xu, Y.; Zhang, B. Recent advances in porous Pt-based nanostructures: Synthesis and electrochemical application. Chem. Soc. Rev. 2014, 43, 2439-2450. [CrossRef]

102. Muench, F.; Kunz, U.; Neetzel, C.; Lauterbach, S.; Kleebe, H.-J.; Ensinger, W. 4-(Dimethylamino)pyridine as a Powerful Auxiliary Reagent in the Electroless Synthesis of Gold Nanotubes. Langmuir 2011, 27, 430-435. [CrossRef]

103. Vlad, A.; Antohe, V.-A.; Martinez-Huerta, J.M.; Ferain, E.; Gohy, J.-F.; Piraux, L. Three-dimensional interconnected $\mathrm{Ni}_{\text {core }}-\mathrm{NiO}_{\text {shell }}$ nanowire networks for lithium microbattery architectures. J. Mater. Chem. A 2016, 4, 1603-1607. [CrossRef]

104. Araujo, E.; Encinas, A.; Velázquez-Galván, Y.; Martínez-Huerta, J.M.; Hamoir, G.; Ferain, E.; Piraux, L. Artificially modified magnetic anisotropy in interconnected nanowire networks. Nanoscale 2015, 7, 1485-1490. [CrossRef]

105. da Câmara Santa Clara Gomes, T.; De La Torre Medina, J.; Lemaitre, M.; Piraux, L. Magnetic and Magnetoresistive Properties of 3D Interconnected NiCo Nanowire Networks. Nanoscale Res. Lett. 2016, 11, 466. [CrossRef] [PubMed]

106. da Câmara Santa Clara Gomes, T.; De La Torre Medina, J.; Velázquez-Galván, Y.G.; Martínez-Huerta, J.M.; Encinas, A.; Piraux, L. Interplay between the magnetic and magneto-transport properties of 3D interconnected nanowire networks. J. Appl. Phys. 2016, 120, 043904. [CrossRef]

107. de la Torre Medina, J.; Gomes, T.D.; Galván, Y.G.; Piraux, L. Large-Scale 3-D Interconnected Ni Nanotube Networks with Controlled Structural and Magnetic Properties. Sci. Rep. 2018, 8, 14555. [CrossRef]

108. Bauer, J.; Meza, L.R.; Schaedler, T.A.; Schwaiger, R.; Zheng, X.; Valdevit, L. Nanolattices: An Emerging Class of Mechanical Metamaterials. Adv. Mater. 2017, 29, 1701850. [CrossRef] [PubMed]

109. Boehme, M.; Ensinger, W. From Nanowheat to Nanograss: A Preparation Method to Achieve Free Standing Nanostructures Having a High Length/Diameter Aspect Ratio. Adv. Eng. Mater. 2011, 13, 373-375. [CrossRef]

110. Yu, S.; Li, N.; Wharton, J.; Martin, C.R. Nano Wheat Fields Prepared by Plasma-Etching Gold Nanowire Containing Membranes. Nano Lett. 2003, 3, 815-818. [CrossRef]

111. McKeown, C.; Rhen, F.M.F. Pt nanotube network with high activity for methanol oxidation. J. Appl. Electrochem. 2018, 48, 165-173. [CrossRef]

112. Barako, M.T.; Roy-Panzer, S.; English, T.S.; Kodama, T.; Asheghi, M.; Kenny, T.W.; Goodson, K.E. Thermal Conduction in Vertically Aligned Copper Nanowire Arrays. ACS Appl. Mater. Interfaces 2015, 7, 19251-19259. [CrossRef]

113. Zhou, Q.; He, J.; Huang, Y.; Chen, Y.; Guo, J.; Nie, B. In situ SERS interrogation of catalytic reaction on three-dimensional gold nanowire carpeted polycarbonate membranes. Anal. Methods 2014, 5, 4625-4632. [CrossRef] 
114. Mollamahalle, Y.B.; Ghorbani, M.; Dolati, A. Electrodeposition of long gold nanotubes in polycarbonate templates as highly sensitive 3D nanoelectrode ensembles. Electrochim. Acta 2012, 75, 157-163. [CrossRef]

115. Mukaibo, H.; Horne, L.P.; Park, D.; Martin, C.R. Controlling the Length of Conical Pores Etched in Ion-Tracked Poly(ethylene terephthalate) Membranes. Small 2009, 5, 2474-2479. [CrossRef]

116. Wang, Y.; Zhu, Y.; Chen, J.; Zeng, Y. Amperometric biosensor based on 3D ordered freestanding porous Pt nanowire array electrode. Nanoscale 2012, 4, 6025-6031. [CrossRef] [PubMed]

117. García, M.; Batalla, P.; Escarpa, A. Metallic and polymeric nanowires for electrochemical sensing and biosensing. Trends Anal. Chem. 2014, 57, 6-22. [CrossRef]

118. Rolison, D.R. Catalytic Nanoarchitectures-The Importance of Nothing and the Unimportance of Periodicity. Science 2003, 299, 1698-1701. [CrossRef]

119. Yoon, H.; Deshpande, D.C.; Ramachandran, V.; Varadan, V.K. Aligned nanowire growth using lithography-assisted bonding of a polycarbonate template for neural probe electrodes. Nanotechnology 2008, 19, 025304. [CrossRef]

120. Roustaie, F.; Bieker, J.; Cicek, R.; Schlaak, H.F. Novel fabrication method for integration of template grown metallic nanocones with controllable tip diameter and apex angle. Microelectron. Eng. 2017, 180, 81-85. [CrossRef]

121. Li, F.; Zhu, M.; Liu, C.; Zhou, W.L.; Wiley, J.B. Patterned Metal Nanowire Arrays from Photolithographically-Modified Templates. J. Am. Chem. Soc. 2006, 128, 13342-13343. [CrossRef] [PubMed]

122. Greiner, A.; Wendorff, J.H. Electrospinning: A Fascinating Method for the Preparation of Ultrathin Fibers. Angew. Chem. Int. Ed. 2007, 46, 5670-5703. [CrossRef]

123. Xue, J.; Xie, J.; Liu, W.; Xia, Y. Electrospun Nanofibers: New Concepts, Materials, and Applications. Acc. Chem. Res. 2017, 50, 1976-1987. [CrossRef]

124. Cavaliere, S.; Subianto, S.; Savych, I.; Jones, D.J.; Roziére, J. Electrospinning: Designed architectures for energy conversion and storage devices. Energy Environ. Sci. 2011, 4, 4761-4785. [CrossRef]

125. Khalil, A.; Lalia, B.S.; Hashaikeh, R.; Khraisheh, M. Electrospun metallic nanowires: Synthesis, characterization, and applications. J. Appl. Phys. 2013, 114, 171301. [CrossRef]

126. Wu, H.; Hu, L.; Rowell, M.W.; Kong, D.; Cha, J.J.; McDonough, J.R.; Zhu, J.; Yang, Y.; McGehee, M.D.; Cui, Y. Electrospun Metal Nanofiber Webs as High-Performance Transparent Electrode. Nano Lett. 2010, 10, 4242-4248. [CrossRef]

127. Kim, J.M.; Joh, H.-U.; Jo, S.M.; Ahn, D.J.; Ha, H.Y.; Hong, S.-A.; Kim, S.-K. Preparation and characterization of $\mathrm{Pt}$ nanowire by electrospinning method for methanol oxidation. Electrochim. Acta 2010, 55, 4827-4835. [CrossRef]

128. Wu, H.; Zhang, R.; Liu, X.; Lin, D.; Pan, W. Electrospinning of Fe, Co and Ni Nanofibers: Synthesis, Assembly, and Magnetic Properties. Chem. Mater. 2007, 19, 3506-3511. [CrossRef]

129. Cho, Y.-B.; Yu, A.; Lee, C.; Kim, M.H.; Lee, Y. Fundamental Study of Facile and Stable Hydrogen Evolution Reaction at Electrospun Ir and Ru Mixed Oxide Nanofibers. ACS Appl. Mater. Interfaces 2018, 10, 541-549. [CrossRef]

130. Gries, K.; Vieker, H.; Gölzhäuser, A.; Agarwal, S.; Greiner, A. Preparation of Continuous Gold Nanowires by Electrospinning of High-Concentration Aqueous Dispersions of Gold Nanoparticles. Small 2012, 8, 1436-1441. [CrossRef]

131. Huang, Y.; Garcia, M.; Habib, S.; Shui, J.; Wagner, F.T.; Zhang, J.; Jorné, J.; Li, J.C.M. Dealloyed PtCo hollow nanowires with ultrathin wall thicknesses and their catalytic durability for the oxygen reduction reaction. J. Mater. Chem. A 2014, 2, 16175-16180. [CrossRef]

132. Yu, A.; Lee, C.; Lee, N.-S.; Kim, M.H.; Lee, Y. Highly Efficient Silver-Cobalt Composite Nanotube Electrocatalysts for Favorable Oxygen Reduction Reaction. ACS Appl. Mater. Interfaces 2016, 8, 32833-32841. [CrossRef]

133. Marx, S.; Jose, M.V.; Andersen, J.D.; Russell, A.J. Electrospun gold nanofiber electrodes for biosensors. Biosens. Bioelectron. 2011, 26, 2981-2986. [CrossRef] [PubMed]

134. Zhang, L.; Gong, X.; Bao, Y.; Zhao, Y.; Xi, M.; Jiang, C.; Fong, H. Electrospun Nanofibrous Membranes Surface-Decorated with Silver Nanoparticles as Flexible and Active/Sensitive Substrates for Surface-Enhanced Raman Scattering. Langmuir 2012, 28, 14433-14440. [CrossRef] [PubMed] 
135. He, H.; Cai, W.; Lin, Y.; Dai, Z. Silver Porous Nanotube Built Three-Dimensional Films with Structural Tunability Based on the Nanofiber Template-Plasma Etching Strategy. Langmuir 2011, 27, 1551-1555. [CrossRef] [PubMed]

136. Shui, J.-I.; Chen, C.; Li, J.C.M. Evolution of Nanoporous Pt-Fe Alloy Nanowires by Dealloying and their Catalytic Property for Oxygen Reduction Reaction. Adv. Funct. Mater. 2011, 21, 3357-3362. [CrossRef]

137. Brodt, M.; Han, T.; Dale, N.; Niangar, E.; Wycisk, R.; Pintauro, P. Fabrication, In-Situ Performance, and Durability of Nanofiber Fuel Cell Electrodes. J. Electrochem. Soc. 2015, 162, F84-F91. [CrossRef]

138. Xiao, Y.; Han, G. High performance platinum nanofibers with interconnecting structure using in dye-sensitized solar cells. Org. Electron. 2016, 37, 239-244. [CrossRef]

139. He, H.; Li, K.; Dong, J.; Xia, J.; Zhang, Y.; Yang, T.; Zhao, X.; Huang, Q.; Zeng, X. Mesoporous Au nanotube-constructed three-dimensional films with excellent SERS performance based on the nanofiber template-displacement strategy. RSC Adv. 2016, 6, 4429-4433. [CrossRef]

140. Li, J.C.M.; Shui, J. Platinum Nanowires Produced by Electrospinning. Nano Lett. 2009, 9, 1307-1314. [CrossRef]

141. Zhao, G.; Yang, F.; Chen, Z.; Liu, Q.; Ji, Y.; Zhang, Y.; Niu, Z.; Mao, J.; Bao, X.; Hu, P.; et al. Metal/oxide interfacial effects on the selective oxidation of primary alcohols. Nat. Commun. 2016, 8, 14039. [CrossRef] [PubMed]

142. Weng, J.; Lu, X.; Gao, P.-X. Nano-Array Integrated Structured Catalysts: A New Paradigm upon Conventional Wash-Coated Monolithic Catalysts? Catalysts 2017, 7, 253. [CrossRef]

143. Kim, J.; Li, Z.; Park, I. Direct synthesis and integration of functional nanostructures in microfluidic devices. Lab Chip 2011, 11, 1946-1951. [CrossRef] [PubMed]

(C) 2018 by the author. Licensee MDPI, Basel, Switzerland. This article is an open access article distributed under the terms and conditions of the Creative Commons Attribution (CC BY) license (http:/ / creativecommons.org/licenses/by/4.0/). 